\title{
1. Modeling single individuals: the journey from psych lab to the app store $^{1}$
}

\author{
Jordan J. Louviere
}

\section{INTRODUCTION}

The purpose of this chapter is to develop the ideas discussed in my keynote address at the ICMC in Leeds in 2010 in more detail. In particular, I will review the choice-based measurement theory and measurement methods known as Best-Worst Scaling (BWS). I will introduce BWS Cases 1 and 2, and extend the ideas from Cases 1 and 2 to Case 3 (aka DECs). En route I will briefly touch on error variance differences and stability of preferences over time. The chapter ends with some conclusions and potential future research directions.

Individual level models (ILMs) are not new. Indeed, psychologists have been interested in ILMs since Thurstone (1927). However, what is surprising is that unlike marketing, transport and applied economics, there historically was little interest in the formal application of sophisticated statistical design theory and methods to "designing" choice experiments. Instead, psychologists tended to rely on paired comparisons and/or ad hoc sets of triples, quadruples, etc. This is particularly surprising in so far as psychologists are much more interested in the underlying processes involved in choice behaviours than other disciplines; hence, one would think that many would have seen the obvious connection between experimental design and one's ability to both test and draw inferences from studies of choice behaviour. Thus, there has been little systematic work in psychology on "design" or the properties of various designs, such as numbers and types of choice sets needed for unbiased, efficient and/or consistent estimates.

The emphasis in psychology, perhaps more than in other fields, has been on developing descriptive representations of human choice processes and deriving their theoretical and measurement properties. So, psychologists can learn from the work in marketing, transport and applied economics 
that focuses on statistical theory and methods for constructing discrete choice experiments, and the other fields can learn about descriptive theories of choice processes from psychology. The latter, in particular, are important in so far as the choice modeling field outside of psychology has gradually trended towards what can be described as little more than mere statistical description. This trend is largely devoid of behavioural understanding, and many of the statistical model specifications describe normative processes that, as should be obvious to anyone, cannot possibly reflect any real choice processes used by humans. Thus, marketing, transport and applied economics could benefit from a return to an interest in the actual process by which humans make choices instead of continuing to spiral off into ever-more complicated, clearly invalid models of human choice processes. More specifically, it is time for the field to return to a more balanced approach in which understanding receives at least as much attention as prediction.

From the standpoint of ILMs, I will focus on individual processes instead of trying to describe a sample from some population statistically. Indeed, individuals have consistently been the focus of attention in psychology, as evidenced by Luce's (1959) work on the choice axiom, and Luce and Suppes (1965) work on the conditions under which rankings are consistent with Luce's model. From the standpoint of ILMs, full or partial rankings of alternatives in choice sets underlies several approaches we've been developing over the past five to seven years. Naturally, use of full or partial rankings to provide more statistical information for modeling discrete choices also is not new. For example, economists and marketers begin to use rank order explosion in the late 1970s and early 1980s, such as Beggs et al. (1981), who used ranking of alternatives to model choices of electric cars; and Chapman and Staelin (1982), who used the Beggs et al. approach to model school choices. However, perhaps more central to this chapter is the work of Chapman (1984), who tried to estimate ILMs from survey data using such rank order explosion ideas, and concluded that one would need too many sets to make the approach practical in survey applications. I personally was very influenced by Chapman's work, and abandoned a stream of research focused on estimating models for single persons.

Of course, full or partial rankings are not the only way that one can obtain sufficient information about choices to be able to estimate ILMs. Hauser (1978) proved that allocation tasks were consistent with conditional logit models; Louviere and Woodworth (1983), Hensher and Louviere (1983) and Hensher et al. (1998) discussed and illustrated the use of such tasks for estimating aggregate-level choice models. Indeed, it is quite surprising that allocation tasks have not been more widely used and/ or have not been used to estimate ILMs. The field clearly could benefit 
from comparisons of traditional "pick the most preferred" tasks with ranking/partial ranking and allocation tasks, and I hope that one outcome of this chapter is that this now will occur.

After largely abandoning work on ILMs for more than 15 years, I returned to this topic in a very tangential manner in the later 1990s. In particular, Donald Anderson and I were asked to help develop a search engine to capture tradeoffs and preferences. After much thought and discussion, it became obvious that one could do this only if one could estimate individual-level tradeoffs and preferences. Earlier, in the late 1980s, I had developed a new choice-based measurement approach known as Best-Worst Scaling (BWS), which Adam Finn and I (Finn and Louviere 1992) introduced in the context of measuring public "concerns" about various major issues, including "food safety". I eventually came to see that BWS could provide measures for single people, and could be extended to the case of discrete choice experiments (DCEs, Louviere et al. 2000) that would be needed to develop a search engine capability. The "tech wreck" hit and our funding ran out, so I worked on these ideas part-time, and focused on convincing Tony Marley that BWS was consistent with work in his PhD thesis (Marley 1968), and that it provided a way to model and measure many subjective (latent) phenomena.

Tony signed on to the project, and since 2003 he and I and others have worked on deriving the formal measurement and representation properties of BWS and illustrating how it can be used by researchers in many fields to replace rating scales and the method of paired comparisons. Indeed, I now regard both rating scales and the method of paired comparisons as obsolete because BWS can do what these methods purport to do in a theoretically consistent and methodologically straightforward manner that requires (typically) many fewer choices than paired comparisons and about as many responses as rating scales. BWS has provided a way to derive measures of latent quantities for single persons for more than 20 years, and later in this chapter we will show how the basic ideas in BWS Cases 1 and 2 can be extended to DCEs to estimate ILMs.

More recently, several researchers have proposed so-called "adaptive" methods to model individuals. Examples include the Adaptive Conjoint Analysis procedures of Sawtooth Software, and work by Toubia et al. (2007) and others. These methods purport to model individuals by sampling and analysis methods that rely on early observations of choices to estimate model parameters by "learning" about preferences and updating choice tasks to refine the estimates based on prior responses. To those familiar with Heckman's (1979) work on "selection bias" (for which he shared the 2000 Nobel Prize in Economics), it should be obvious that these approaches sample on the dependent variable, and so are subject 
to selection bias. Proponents of this and similar approaches typically also claim that one can quickly and easily focus in on ILMs using this approach. However, as I will show later in this chapter, it is hard to see how these methods can produce (1) fewer choice sets and/or (2) estimates that are as statistically efficient as the approaches we discuss. There also are other issues with individualization of choice tasks, such as confounding preferences and scale with the individualization; given emerging evidence in our research centre and elsewhere that there may be demand artifacts associated with different designs, it is unclear how to interpret modeling results if one individualizes due to the inherent confound(s).

\section{BEST-WORST SCALING (BWS): THEORY AND METHODS}

BWS focuses on situations in which individuals face choice sets with $\geq 3$ options, and select the "Best" (most preferred, biggest, etc.) and "Worst" (least preferred, smallest, etc.) options from those choice (comparison) sets. Unlike traditional "pick one" (i.e., "best") choice tasks, a person can make best and worst choices in several ways; each "way" implies a different choice process. For example, a person can simultaneously choose the two options farthest apart on the underlying subjective (latent) scale, which reflects what is called a "maximum difference" (or, "Max-Diff") choice process (Finn and Louviere 1992). Other strategies (processes) include: (1) choosing Best, then Worst, then Next Best, etc., reflecting a type of sequential best-worst choice strategy or process; (2) choosing Worst, then Next Worst, then Best, reflecting a different sequential best-worst process; (3) choosing Best, then Next Best, then Next Worst, another sequential process; and (4) other possibilities. In the USA in particular, and in marketing research more specifically, many academic and applied researchers assume that individuals simultaneously choose the Best and Worst/Worst and Best pair that exhibits the maximum difference on the latent scale (Max-Diff), but this is only one possible process. Unfortunately for proponents of this process, work in my research centre (The Centre for the Study of Choice, or "CenSoC") over the past several years suggests that this strategy is never used by any humans.

More generally, each "way" that a person might use to choose the Best and the Worst options in a choice set represents a different "choice process". Each process implies a different statistical choice model with a potentially different likelihood function. From a scientific standpoint, our objective should be to try to identify the "correct" choice process for each person, and develop a statistical model of that process that can be used to measure each option on a latent scale. 
Balanced Incomplete Block Design

\begin{tabular}{|c|c|c|c|c|c|c|c|c|c|}
\hline \multirow{2}{*}{$\frac{\text { Block }}{1}$} & \multicolumn{3}{|c|}{$\begin{array}{l}\text { Options in } \\
\text { blocks }\end{array}$} & \multirow{2}{*}{$\frac{\text { Block }}{1}$} & \multicolumn{3}{|c|}{ Options in blocks } & \multirow{2}{*}{$\begin{array}{l}\text { Most prefered } \\
\text { United/Cont }\end{array}$} & \multirow{2}{*}{$\frac{\text { Least prefered }}{\text { Delta }}$} \\
\hline & 2 & 6 & 4 & & Air France/KLM & United/Cont & Delta & & \\
\hline 2 & 1 & 4 & 5 & 2 & American & Delta & Lufthansa & Lufthansa & Delta \\
\hline 3 & 4 & 7 & 3 & 3 & Delta & Virgin & British Airways & Virgin & Delta \\
\hline 4 & 3 & 2 & 1 & 4 & British Airways & Air France/KLM & American & British Airways & American \\
\hline 5 & 7 & 5 & 2 & 5 & Virgin & Lufthansa & Air France/KLM & Lufthansa & Air France/KLM \\
\hline 6 & 6 & 1 & 7 & 6 & United/Cont & American & Virgin & United/Cont & American \\
\hline 7 & 5 & 3 & 6 & 7 & Lufthansa & British Airways & United/Cont & United/Cont & British Airways \\
\hline
\end{tabular}

\begin{tabular}{|c|c|c|c|c|c|c|c|c|c|c|c|c|}
\hline \multicolumn{5}{|c|}{ BIBD } & \multicolumn{8}{|c|}{ Most \& Least preferred choice } \\
\hline \multirow{2}{*}{$\frac{\text { Block }}{1}$} & \multicolumn{4}{|c|}{ Options in blocks } & \multirow{2}{*}{\begin{tabular}{|c|} 
Block \\
1
\end{tabular}} & \multicolumn{4}{|c|}{ Options in each blocks } & \multirow{2}{*}{$\begin{array}{c}\text { Most } \\
\text { prefered }\end{array}$} & \multirow{2}{*}{$\begin{array}{c}\begin{array}{c}\text { Least } \\
\text { prefered }\end{array} \\
\text { American }\end{array}$} & \multirow{2}{*}{$\frac{\text { 2nd Most }}{\text { Virgin }}$} \\
\hline & 1 & 3 & 7 & 5 & & American & British Airways & Virgin & Lufthansa & & & \\
\hline 2 & 6 & 7 & 2 & 3 & 2 & United/Cont & Virgin & Air France/KLM & British Airways & United/Cont & Air Fr/KLM & Virgin \\
\hline 3 & 5 & 2 & 1 & 6 & 3 & Lufthansa & Air France/KLM & American & United/Cont & United/Cont & American & Lufthansa \\
\hline 4 & 7 & 5 & 6 & 4 & 4 & Virgin & Lufthansa & United/Cont & Delta & United/Cont & Delta & Lufthansa \\
\hline 5 & 4 & 6 & 3 & 1 & 5 & Delta & United/Cont & British Airways & American & United/Cont & Delta & British Air \\
\hline 6 & 3 & 4 & 5 & 2 & 6 & British Airways & Delta & Lufthansa & Air France/KLM & Lufthansa & Delta & British Air \\
\hline 7 & 2 & 1 & 4 & 7 & 7 & Air France/KLM & American & Delta & Virgin & Virgin & Delta & Virgin \\
\hline
\end{tabular}

Figure 1.1 Using a BIBD to make comparison sets with example "choices"

\section{CASE 1 BEST-WORST SCALING (BWS)}

I illustrate Case 1 BWS with an example that involves measuring preferences for airlines flying to/from USA/UK. I design, implement and compare two BWS Case 1 tasks involving seven airlines; each choice (comparison) set has three or four airlines, respectively. In BWS parlance, each of the seven airlines is a choice object (choice option, alternative). I assign the seven airlines to choice sets to construct a choice task where I can observe best and worst choices. In Case 1 BWS, options are assigned to sets (choice set construction) using a B(alanced) I(ncomplete) B(lock) D(esign). Figure 1.1 illustrates two BIBDs for seven airlines, with associated hypothetical best and worst choices.

The two BIBD-designed tasks produce seven best and worst choices. As noted by Manski and McFadden (1981), and Louviere and Woodworth (1983), choice data and choice experiments are a sparse, incomplete contingency (crosstab) table. The marginal counts from these tables contain all the statistical information needed to estimate various types of choice models. Thus, one can count the choices to calculate the choice (frequency) counts for each airline. These counts represent a first approximation to the unknown measures (utilities) of interest for each person, and are shown in Table 1.1. Experience with hundreds of applications of Case 1 suggests that the counts provide sufficient information to compare and classify 
Table 1.1 Choices observed in BIBD-generated comparison sets

\begin{tabular}{lccccccc}
\hline \multirow{2}{*}{ Airlines } & \multicolumn{3}{c}{ BIBD 1 } & & \multicolumn{3}{c}{ BIBD 2 } \\
\cline { 2 - 3 } \cline { 7 - 8 } & Most & Least & Most-Least & & Most & Least & Most-Least \\
\hline Air France & 0 & 1 & -1 & & 0 & 1 & -1 \\
American & 0 & 2 & -2 & & 0 & 2 & -2 \\
British Airways & 1 & 1 & 0 & & 0 & 0 & 0 \\
Delta & 0 & 3 & -3 & & 0 & 4 & -4 \\
Lufthansa & 2 & 0 & 2 & & 2 & 0 & 2 \\
United/Continental & 3 & 0 & 3 & & 4 & 0 & 4 \\
Virgin & 1 & 0 & 1 & & 1 & 0 & 1 \\
\hline
\end{tabular}

individuals, such as using cluster analytic or other taxonomic methods to identify groups of relatively homogeneous individuals.

As has been well-known since Luce (1959), the choice totals are consistent with the unknown parameters (scale values or measures) in the Luce model: $P(i \mid C)=V_{i} / \Sigma_{j} V_{j}$, for all $j$ in $C$. If Best counts $=1 /$ (Worst counts), then the square root of (Best/Worst) is proportional to the Best counts, and the natural log of that quantity is linearly related to the conditional logit utilities (scale values). Typically, the natural log of the square root (Best/ Worst) is linearly related to what I call "Best Worst Scores", which are the Best minus Worst differences. It would be nice to have a formal proof of this relationship, so for the present, it should be regarded only as an empirical regularity observed in many datasets. Naturally, many people are likely not to be perfect choosers, and so there will be errors in the counts. Allowing for errors, of course, puts the analyst in the familiar world of random utility-based choice models, making it highly unlikely that one can estimate a model for a single person from the sparse choice data shown in Table 1.1. However, it hopefully is obvious that as one begins to aggregate subsets of individuals, it becomes more likely that one can estimate various forms of statistical choice models from Case 1 choice data.

The two results for the Most minus Least differences ("BWS scores") for each BIBD are graphed in Figure 1.2; they obviously are proportional (a general empirical result).

Thus, one can calculate individual-level Most minus Least count scores, but one cannot calculate Most counts divided by Least count due to some zero Least choices. However, as earlier noted, the Most and Least choices provide a full or partial ordering of the options; hence, one can expand (explode) the choice data into implied choices using ideas in Beggs et al. (1981) and Chapman and Staelin (1982). Specifically, we can expand the data to up to $\mathrm{J}-1$ independent choice sets for $\mathrm{J}$ options in a set. The implied 


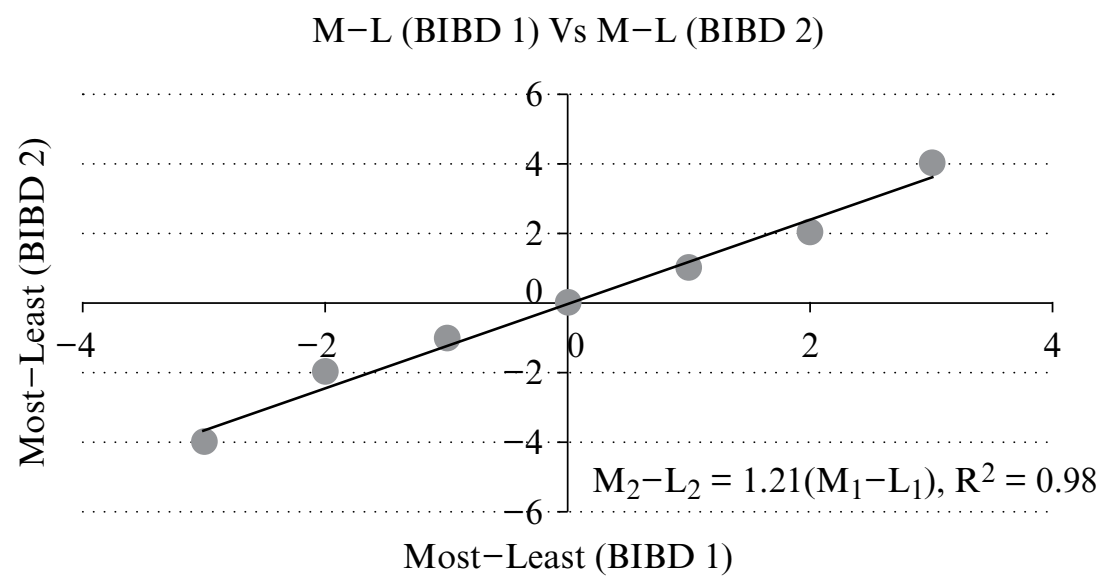

Figure 1.2 Best minus worst totals for the two BIBDs

rankings from the Most and Least choices for the BIBD with three options per set are in Table 1.2.

We also expand the observed rankings using the approach proposed by Louviere et al. (2008), which involves assigning an expected Most choice count with each rank equal to the total choices that would be observed for that ranking in all possible choice sets. These totals are rank $1=4$, rank $2=2$ and rank $3=1$; for Least choices the expected counts are reversed (ie, 1, 2, 4). We calculate the square root of Most/Least and the natural $\log$ of that quantity, as shown in Table 1.3. The accompanying graph in Figure 1.3 relates the mean choice counts to the other three columns. The graph clearly shows that all measures are approximately linearly related, suggesting that the Most minus Least totals are a reasonable first approximation for comparing and classifying individuals.

I now provide two more examples to show this is not a fluke/accident, but holds more generally.

\section{TWO EMPIRICAL EXAMPLES}

\subsection{Choosing wines for a dinner party}

The first example involves measuring preferences for wines for a CenSoC stakeholder dinner for 20 people. Typically, wine choices are left to the venue, and few such choices are memorable. So, I wanted to see if I could do a better job than the venue. I selected 13 wines from a large retailer with 
Table 1.2 Implied ranking from Best and Worst choices

\begin{tabular}{|c|c|c|c|c|c|c|c|}
\hline \multicolumn{4}{|c|}{ Observed Rank \& Choice } & \multicolumn{4}{|c|}{ Implied Second Sets Rank \& Choice } \\
\hline Set & Airline & Rank & Most & Set & Airline & Rank & Most \\
\hline 1 & $\mathrm{AF}$ & 2 & 0 & 1 & $\mathrm{AF}$ & 1 & 1 \\
\hline 1 & UN & 1 & 1 & 1 & $\mathrm{DE}$ & 2 & 0 \\
\hline 1 & $\mathrm{DE}$ & 3 & 0 & 2 & $\mathrm{AM}$ & 1 & 1 \\
\hline 2 & $\mathrm{AM}$ & 2 & 0 & 2 & $\mathrm{DE}$ & 2 & 0 \\
\hline 2 & $\mathrm{DE}$ & 3 & 0 & 3 & $\mathrm{DE}$ & 1 & 0 \\
\hline 2 & LU & 1 & 1 & 3 & BA & 2 & 1 \\
\hline 3 & DE & 3 & 0 & 4 & $\mathrm{AF}$ & 1 & 1 \\
\hline 3 & VI & 1 & 1 & 4 & $\mathrm{AM}$ & 2 & 0 \\
\hline 3 & BA & 2 & 0 & 5 & VI & 1 & 1 \\
\hline 4 & $\mathrm{BA}$ & 1 & 1 & 5 & $\mathrm{AF}$ & 2 & 0 \\
\hline 4 & $\mathrm{AF}$ & 2 & 0 & 6 & $\mathrm{AM}$ & 1 & 0 \\
\hline 4 & $\mathrm{AM}$ & 3 & 0 & 6 & VI & 2 & 1 \\
\hline 5 & VI & 2 & 0 & 7 & LU & 1 & 1 \\
\hline 5 & LU & 1 & 1 & 7 & BA & 2 & 0 \\
\hline 5 & $\mathrm{AF}$ & 3 & 0 & & & & \\
\hline 6 & UN & 1 & 1 & & & & \\
\hline 6 & $\mathrm{AM}$ & 3 & 0 & & & & \\
\hline 6 & VI & 2 & 0 & & & & \\
\hline 7 & LU & 2 & 0 & & & & \\
\hline 7 & BA & 3 & 0 & & & & \\
\hline 7 & UN & 1 & 1 & & & & \\
\hline
\end{tabular}

Table 1.3 Square root of Most/Least compare with other quantities

\begin{tabular}{lcccr}
\hline Airline & Mean choice counts & \multicolumn{2}{c}{ Louviere et al. 2008 } & \multirow{2}{*}{ M-L } \\
\cline { 3 - 4 } & & SQML & Ln(SQML) & \\
\hline AF & .3333 & .8333 & -.2310 & -1 \\
AM & .1667 & .6667 & -.4621 & -2 \\
BA & .4000 & 1.0000 & -.1386 & 0 \\
DE & .0000 & .5000 & -.6931 & -3 \\
LU & .7500 & 1.5000 & .3466 & 2 \\
UN & 1.0000 & 2.0000 & .6931 & 3 \\
VI & .6000 & 1.2000 & .1386 & 1 \\
\hline
\end{tabular}

a tasting panel that rates the wines. As in example one, I used a BIBD to assign the 13 wines to 13 choice (comparison) sets with four wines per set. I formatted the sets into a survey and emailed them to the invitees, asking them to make most and least preferred choices in each set. The wines and 


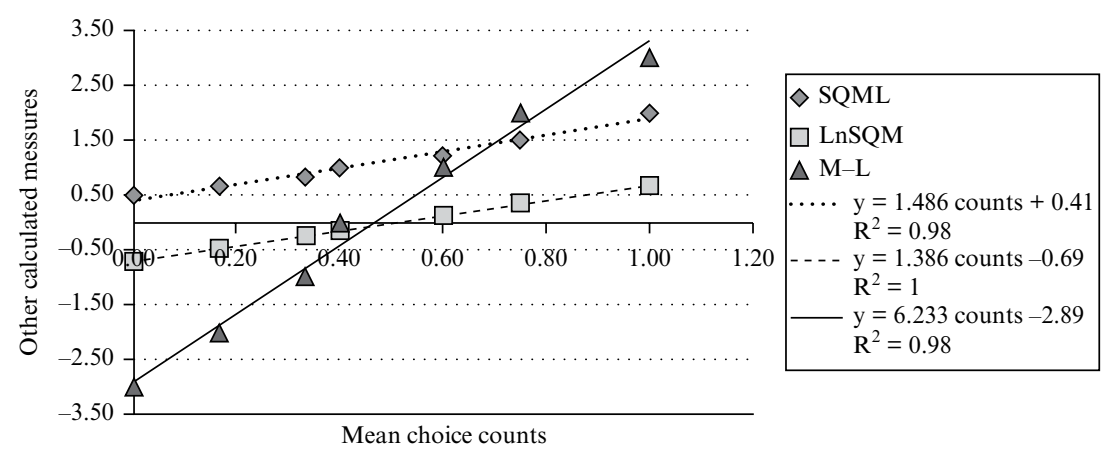

Figure 1.3 Expanded choice counts compared with other calculations

BIBD are shown below in Figure 1.4 (each wine was named exactly as in online and print catalogues, including points (100) by a tasting panel), with two choice sets from the choice task also shown.

As before, I counted the choices of each wine as most and least preferred, and calculated Most minus Least scores, as shown in Table 1.4. Because I needed a red and a white wine, I selected the top scoring red and white, highlighted in bold in the table. The wines were a big success, with lots of positive comments from the guests. Because I also had a revealed preference measure of choices (bottles consumed) I compared this to the M-L measures, as shown.

I used a Luce (1959) model with only Most counts to predict choices. That is, I calculated the following expressions:

$$
\begin{gathered}
\mathrm{P}(\text { Ch. Reynella })=V_{C R} /\left(V_{C R}+V_{R W}\right) \\
\mathrm{P}(\text { Ravenswood })=1-\mathrm{P}(\text { Ch. Reynella }) .
\end{gathered}
$$

The predicted and observed choices are in Table 1.5; the results suggest that our dinner guests chose wines at the dinner consistent with the preferences they expressed in advance.

\subsection{Citizen choices of possible public transport improvements in Sydney}

A second example involves measuring preferences for public transport changes for residents of the Sydney Metropolitan Area (Australia). By way of background, the quality/service of Sydney's public transport systematically declined from 2000 onwards. The elected government of the day was fairly unresponsive to the declines and/or to citizen 


\begin{tabular}{|c|c|c|c|c|c|c|}
\hline 1 & Bests Great Western Bin 1 Shiraz 2006 (94 pts) & Block & \multicolumn{4}{|c|}{ BIBD } \\
\hline 2 & Taylors Jaraman Riesling 2008 (94 pts) & 1 & 11 & 8 & 5 & 2 \\
\hline 3 & O’Leary Walker Polish Hill Riesling 2008 (95 pts) & 2 & 7 & 1 & 6 & 5 \\
\hline 4 & Chateau Reynella Shiraz 2006 (97 pts) & 3 & 12 & 5 & 4 & 10 \\
\hline 5 & Lalla Gully Pipers River Tassie Pino Gris 2008 (93 pts) & 4 & 5 & 13 & 9 & 3 \\
\hline 6 & Helm Classic Dry Riesling 2008 (95 pts) & 5 & 4 & 3 & 2 & 1 \\
\hline 7 & Chalice Bridge Margaret River Chardonnay 2007 (93 pts) & 6 & 13 & 2 & 10 & 7 \\
\hline 8 & Taylors Jaraman Chardonnay 2006 (93 pts) & & 2 & 6 & 12 & 9 \\
\hline 9 & Jacobs Creek Reserve CabSauv 2005 (93 pts) & 8 & $\begin{array}{l}1 \\
9\end{array}$ & $\begin{array}{l}12 \\
11\end{array}$ & 11 & 13 \\
\hline 10 & Ravenshead Clare Valley Riesling 2008 (95 pts) & 10 & 6 & 10 & 3 & 11 \\
\hline 11 & Capel Vale Mt, Barker Shiraz 2007 (94 pts) & 11 & 10 & 9 & 1 & 8 \\
\hline 12 & Da Vinci Chianti Riserva 2005 (93 pts) & 12 & 3 & 7 & 8 & 12 \\
\hline 13 & Amberley Margaret River Shiraz Viogner 2007 (94 pts) & 13 & 8 & 4 & 13 & 6 \\
\hline
\end{tabular}

\begin{tabular}{|c|c|c|}
\hline $\begin{array}{c}\text { Most } \\
\text { Prefer }\end{array}$ & Set 1 & $\begin{array}{c}\text { Least } \\
\text { Prefer }\end{array}$ \\
\hline$\square$ & Bests Great Western Bin 1 Shiraz 2006 (94 pts) & $\square$ \\
\hline$\square$ & Taylors Jaraman Riesling 2008 (94 pts) & $\square$ \\
\hline$\square$ & O'Leary Walker Polish Hill Riesling 2008 (95 pts) & $\square$ \\
\hline$\square$ & Chateau Reynella Shiraz 2006 (97 pts) & $\square$ \\
\hline
\end{tabular}

\begin{tabular}{|c|c|c|}
\hline $\begin{array}{c}\text { Most } \\
\text { Prefer }\end{array}$ & Set 2 & $\begin{array}{c}\text { Least } \\
\text { Prefer }\end{array}$ \\
\hline$\square$ & Lalla Gully Pipers River Tassie Pinol Gris 2008 (93 pts) & $\square$ \\
\hline$\square$ & Helm Classic Dry Riesling 2008 (95 pts) & $\square$ \\
\hline$\square$ & Chalice Bridge Margaret River Chardonnay 2007 (93 pts) & $\square$ \\
\hline$\square$ & O'Leary Walker Polish Hill Riesling 2008 (95 pts) & $\square$ \\
\hline
\end{tabular}

Figure 1.4 Wines in example, BIBD used to make sets and two example tasks

dissatisfaction with them. Eventually, the situation reached a point where the Sydney Morning Herald commissioned its own independent inquiry into the public transport system and future transport preferences/needs. CenSoC was asked to undertake the research associated with the inquiry. This was a complex study, with several survey components. I discuss only a component that aimed to measure public preferences for nine potential short-term improvements to public transport systems and services. As in the two previous examples, the nine potential improvements were placed into 12 choice sets using a BIBD. We randomly sampled 2400 Sydney Metro residents above the age of 18 from the Pureprofile online Australian panel. All respondents answered this Case 1 BWS survey by 
Table 1.4 Most and Least preferred counts and differences in counts

\begin{tabular}{lrrr}
\hline Wines & Most & Least & M-L \\
\hline Amberley Margaret River Shiraz Viogner 2007 & 16 & 7 & 9 \\
Bests Great Western Bin 1 Shiraz 2006 & 13 & 9 & 4 \\
Capel Vale Mt. Barker Shiraz 2007 & 18 & 8 & 10 \\
Chalice Bridge Margaret River Chardonnay 2007 & 7 & 22 & -15 \\
Chateau Reynella Shiraz 2006 & $\mathbf{3 8}$ & $\mathbf{0}$ & $\mathbf{3 8}$ \\
Da Vinci Chianti Riserva 2005 & 4 & 19 & -15 \\
Helm Classic Dry Riesling 2008 & 7 & 14 & -7 \\
Jacobs Creek Reserve CabSauv 2005 & 8 & 17 & -9 \\
Lalla Gully Pipers River Tassie Pinot Gris 2008 & 15 & 9 & 6 \\
O'Leary Walker Polish Hill Riesling 2008 & 11 & 11 & 0 \\
Ravenshead Clare Valley Riesling 2008 & $\mathbf{1 3}$ & $\mathbf{5}$ & $\mathbf{8}$ \\
Taylors Jaraman Chardonnay 2006 & 2 & 20 & -19 \\
Taylors Jaraman Riesling 2008 & 4 & 14 & -10 \\
\hline
\end{tabular}

Table 1.5 Observed and predicted wine choice proportions

\begin{tabular}{lcc}
\hline Wine & Counts: P(Most) & Bottles consumed: $\mathrm{P}($ consumed $)$ \\
\hline Chateau Reynella & $38(0.745)$ & $11(0.733)$ \\
Ravenswood & $13(0.254)$ & $4(0.267)$ \\
\hline
\end{tabular}

choosing which short-term improvements they thought should receive most and least priority. The 12 sets each displayed three of the short-term improvements, so best and worst choices give a complete ranking, as shown in Figure 1.5.

The choice data were analysed with the Scale-Adjusted Latent Class Model (SALCMs) approach developed by Magidson and Vermunt (2007), which simultaneously classifies people into scale (error variance) classes and preference classes. We briefly summarize the results in Figure 1.6. The numbers in the figure are the square roots of the ratio of most to least counts. As earlier noted, these numbers are proportional to Most counts, which in turn are measures associated with Luce (1959) models. This implies that the numbers are on ratio scales, suggesting that respondents give improved bus services on major routes about four times the priority given to new cycleways and more bicycle and scooter parking. Clear priorities were: (1) improve peak rail capacity, (2) improve bus services on major routes, and (3) improve off-peak trains between major centres. Three segments emerged from the SALCM results: residents who want (1) better peak rail and improved off-peak rail and bus services (48 per cent of 

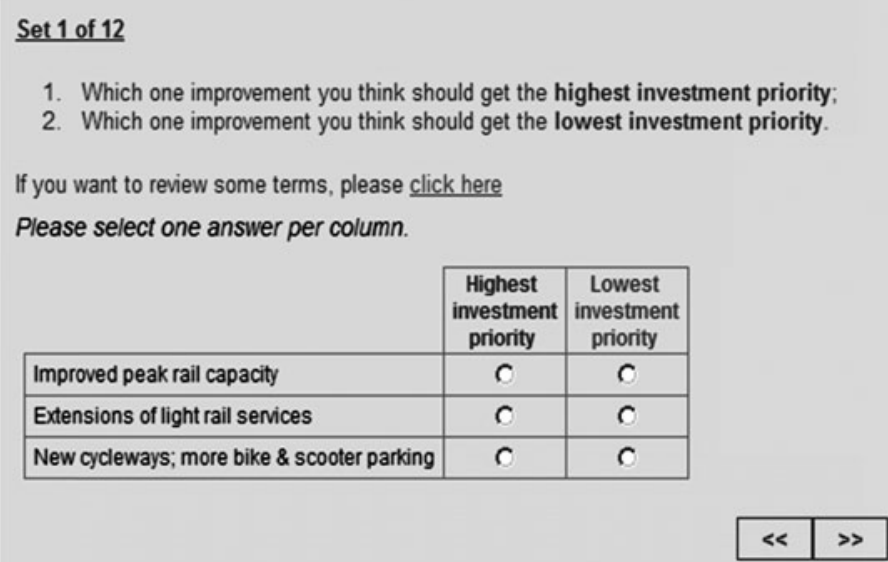

Figure 1.5 Example best-worst comparison set for public transport study

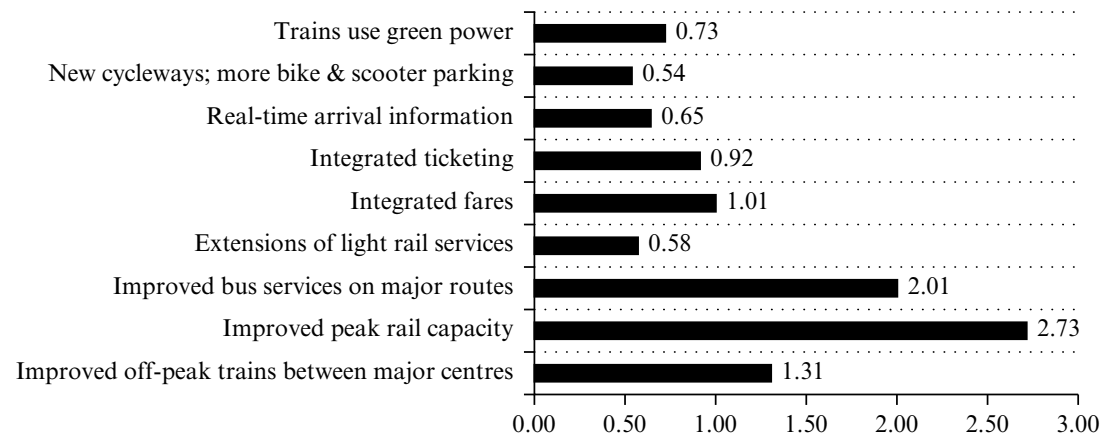

Figure 1.6 Sample mean values of SQRT(most/least) for transport study

sample); (2) integrated ticketing and fares, as well as better peak rail and bus services ( 27 per cent of sample); and (3) better peak rail and trains using more green power ( 25 per cent of sample). We used the segments to inform the analysis of other choice-based measurement survey components.

\section{CASE 2 BWS}

BWS Case 2 (Marley et al. 2008) deals with how individuals choose the best and worst levels in a (conjoint) profile (Louviere 1994). That is, each individual evaluates one multi-attribute choice option at a time, and chooses the best and worst levels associated with each option. Unlike 
DCEs (Case 3 BWS), one designs $\mathbf{J}$ total attribute level combinations known as "profiles" (Green 1974; Louviere 1988). The associated Case 2 task involves presenting all or a subset of the $\mathbf{J}$ profiles one at a time to the survey respondents, who are asked to choose one level as best and a second level as worst in each profile. These choices allow one to place all the attribute levels on a common subjective (latent) scale. Case 2 BWS provides information that cannot be obtained from Cases 1 and 3 , such as whether people "see" differences in the levels of a particular attribute. That is, a person can seem to ignore an attribute, but this result may in fact be due to an experimental fault, such as insufficient variability in the levels.

BWS Case 2 can be viewed in two ways: One can (1) estimate A(lternative) S(pecific) C(onstants) for each attribute level and/or (2) estimate ASCs for each attribute that represent the mean (average) latent values for the attribute, as well as the traditional "effects" (model parameter estimates) associated with the levels of the attribute. Case 2 provides potentially complimentary information to traditional DCEs, and is an interesting task in its own right. There are few prior examples of Case 2, so I present only one example here.

\subsection{Example: choosing most and least preferred levels of emission trading plans}

Like many countries, Australia debated whether to initiate an emissions trading scheme (ETS). The Federal Government passed legislation to initiate a carbon tax that began July 1, 2012. CenSoC asked Australian citizens of voting age about their preferences for ETS plans in 2008, 2009 and 2010 to measure and model public preferences for different components (attributes) of ETS options. I discuss one subcomponent of a larger research effort, namely a Case 2 survey completed by a randomly chosen subsample of 388 people recruited from the Pureprofile online panel in Australia. An example of the task is shown in Figure 1.7, which also shows the ETS attributes and some of their levels.

In Table 1.6 I tabulate the mean Most minus Least choice counts for

\begin{tabular}{|l|c|c|c|}
\hline Features of ETS plan & Most prefer & Plan 1 & Least prefer \\
\hline Start Year & & 2010 & \\
\hline Use the revenues to & $\mathrm{X}$ & reduce the GST & \\
\hline Invest 20\% of revenues in R\&D & & Yes & \\
\hline Exempt transport & & No & \\
\hline Special treatment for energy intensives & & Yes & $X$ \\
\hline
\end{tabular}

Figure 1.7 Example comparison set for ETS best-worst Case 2 task 
Table 1.6 Descriptive Most minus Least statistics across people

\begin{tabular}{lcrrrrr}
\hline Level & N & Mean & SE & T-stat & SD & Rank \\
\hline Start 2010 & 388 & 1.281 & 0.202 & 6.048 & 4.172 & 3 \\
Start 2012 & 388 & -1.711 & 0.200 & -8.556 & 3.940 & 10 \\
\$ to poor/seniors & $\mathbf{3 8 8}$ & $\mathbf{1 . 6 8 8}$ & $\mathbf{0 . 2 2 6}$ & $\mathbf{7 . 4 5 4}$ & $\mathbf{4 . 4 6 1}$ & $\mathbf{2}$ \\
\$ to reduce GST & $\mathbf{3 8 8}$ & $\mathbf{2 . 7 3 2}$ & $\mathbf{0 . 1 7 7}$ & $\mathbf{1 5 . 4 5 1}$ & $\mathbf{3 . 4 8 3}$ & $\mathbf{1}$ \\
Don't invest in R\&D & 388 & -1.487 & 0.128 & -11.593 & 2.527 & 9 \\
Invest in R\&D & 388 & 1.015 & 0.157 & 6.480 & 3.087 & 4 \\
Do not exempt Transport & 388 & -1.023 & 0.126 & -8.129 & 2.479 & 8 \\
Exempt Transport & 388 & -0.938 & 0.154 & -6.082 & 3.038 & 7 \\
Do not exempt Energy & 388 & -0.897 & 0.122 & -7.367 & 2.398 & 6 \\
Exempt Energy & 388 & -0.660 & 0.149 & -4.430 & 2.937 & 5 \\
\hline
\end{tabular}

the sample, along with descriptive statistics for the sample. The results in the table are calculated from the individual level BWS scores (388 best minus worst scores); so, the table is an analogue of a random coefficients analysis. The rows highlighted in bold are the most preferred levels, which involve how to use the revenues raised by the ETS. The rows highlighted in italic are the least preferred levels, which are delaying the ETS start date and not investing 25 per cent of the revenues in research and development in energy efficiency and/or carbon reduction technologies.

Naturally, the table can mask individual differences, which in this case could be due to individual differences in (1) preferences for ETS component/attribute levels, (2) choice consistency (3) model misspecification, or (4) combinations of the foregoing. In the interests of space, I do not reproduce the results of a Scale-Adjusted Latent Class Model that we estimated to study these issues, but I can summarize the results as follows: We identified nine classes that differed most on start year and how to use revenues from the ETS. Other, smaller differences were observed for other attribute levels across classes.

It hopefully should be clear that one can use BWS Cases 1 and 2 to obtain measures for single people, and that these measures are reasonable first approximations to more refined measures that can be derived from choice models that allow for errors, preference differences, etc. Now we show that this can be extended to discrete choice experiments.

\section{BWS CASE 3: BEST-WORST WITH DISCRETE CHOICE EXPERIMENTS (DCE)}

Many choice modeling researchers probably will ask why one would want to model individuals as we already can model samples of individuals and/ 
or we can use existing random coefficient and Latent Class statistical choice models to infer (compute) parameter estimates for single people. One reason is academic; that is, the topic itself is academically interesting and potentially important. Other reasons include (1) a need to test "topdown" model assumptions, which as previously noted are very strong and primarily statistical; (2) to provide a different way to study unobserved variability within and between people; (3) the natural unit of choice analysis is the "individual"; (4) one is interested in the choice process itself and differences in individual choice processes, not merely statistical descriptions; and (5) many other reasons. There also are practical reasons to be interested in modeling individuals, such as providing (1) a simpler way to model individual choices and simulate choice-related outcomes of policy interest; (2) a choice of models for researchers; and (3) simple ways for practitioners to approximate complex choice models and decrease chances of mistakes.

Although I do not discuss it in this chapter, CenSoC team members are engaged in ongoing work on individual-level models that goes well beyond what I discuss here. One can keep up with current and ongoing developments via the CenSoC website and working paper series (http://www. censoc.uts.edu.au/researchoutput/paper.html). These teams have achieved the following: (1) an estimation approach that guarantees convergence for individuals even when there are "perfect classifiers" associated with the choices; and (2) new ways to do model selection on individuals to greatly improve insights about process and inference. We expect papers on these results to be available in early 2013.

We now discuss the intuition underlying how and why one can model individuals using best and worst tasks with DCEs. As earlier noted under Case 1, it is important to recognize that DCEs are incomplete, sparse contingency (crosstab) tables (e.g., Manski and McFadden 1981, p.5; Louviere and Woodworth 1983). Louviere and Woodworth (1983) noted that properly designed DCEs provide choice counts for each level of each attribute, and these choice counts contain all the necessary statistical information for estimating conditional logit models. Thus, if individuals' choices are consistent with a conditional logit model, choice counts from a properly designed DCE provide all the information needed to model each person. So, a key factor in modeling individuals is to construct appropriate designs for DCEs that identify the model parameters of interest and allow them to be estimated. The purpose of Case 3 best and worst choices is to obtain sufficient information about the choices in each choice set to enable model estimation. That is, in a vast majority of cases, one needs more information than what one has from observing only first (best) choices to estimate ILMs. 
Extra choice information traditionally was obtained by asking people to choose from a (fairly) large number of choice sets, an approach common in psychology but rarely practical in applied survey settings. So, the purpose of best and worst choices is to provide a partial or full ranking of the choice options in each set to allow one to "expand" the data into additional implied choice sets that provide extra statistical information. The prior examples and discussion of BWS Cases 1 and 2 indicate that one can calculate choice counts for each attribute level for each person if a DCE is suitably designed. Thus, in principle, asking best and worst choices in DCE surveys can provide statistical information needed to model each person. We now show ways to do this.

\subsection{Choice frequency counts from best and worst choices}

It is useful to recall how Louviere and Woodworth (1983) viewed the problem of designing DCEs. That is, they proposed an approach that involved first designing (constructing) conjoint profiles (as in BWS Case 2), and then using a $2^{\mathrm{J}}$ orthogonal fractional factorial design to assign the profiles to sets. This approach is analogous to using a BIBD in BWS Case 1. That is, profiles represent choice objects (options, alternatives), and the objective is to assign them to sets in such as way that the effects of each level of each attribute are identified and can be estimated. An even better objective is for the assignment to have good statistical properties, such as good efficiency properties. Again, we can return to Louviere and Woodworth (1983), who showed in an Appendix to their paper that using $2^{\mathrm{J}}$ orthogonal fractional factorial designs to assign profiles to sets was nearly optimally efficient. BIBDs also lead to relatively efficient estimates, and have the same advantages as $2^{\mathrm{J}}$ orthogonal fractional factorial designs, namely (1) the choice options appear and co-appear equally often, and (2) the resulting design matrix allows independent estimation of the attribute levels effects. That is, one can calculate marginal effects (choice frequency counts) for each attribute level from choices in DCEs designed using a $2^{\mathrm{J}}$ orthogonal fractional factorial design or a BIBD to assign choice options to sets.

Unfortunately, using $2^{\mathrm{J}}$ orthogonal fractional factorial designs to assign profiles to sets often leads to choice sets of unequal sizes. While not undesirable in principle, different choice sets sizes may produce demand artefacts, by which I mean that respondents may think a survey is "about" the different choice set sizes and begin to make choices in ways that they think they are "supposed to", given what they hypothesize the "real objectives" of the survey are. BIBDs ensure this artefact cannot occur because all choice sets are the same size. To understand how and why this works, 
Table 1.7 Combining a profile design with a $2^{J}$ design

\begin{tabular}{|c|c|c|c|c|c|c|c|c|}
\hline $\begin{array}{l}\text { Design } \\
\text { Profiles }\end{array}$ & 1 & 2 & 3 & 4 & 5 & 6 & 7 & 8 \\
\hline Start date & 2010 & 2010 & 2010 & 2010 & 2012 & 2012 & 2012 & 2012 \\
\hline \multirow{2}{*}{$\begin{array}{l}\text { How to use } \\
\text { revenues }\end{array}$} & reduce & reduce & Snrs \& & Snrs \& & reduce & reduce & Snrs \& & Snrs \& \\
\hline & GST & GST & Poor & Poor & GST & GST & Poor & Poor \\
\hline $\begin{array}{c}\text { Invest } 20 \% \\
\text { in R\&D }\end{array}$ & No & Yes & No & Yes & No & Yes & No & Yes \\
\hline $\begin{array}{l}\text { Exempt } \\
\text { transport }\end{array}$ & No & No & Yes & Yes & Yes & Yes & No & No \\
\hline $\begin{array}{l}\text { Exempt } \\
\text { energy }\end{array}$ & No & Yes & Yes & No & No & Yes & Yes & No \\
\hline Act alone & No & Yes & Yes & No & Yes & No & No & Yes \\
\hline Set & option1 & option 2 & option3 & option4 & option 5 & option6 & option7 & option8 \\
\hline 1 & 0 & 0 & 0 & 0 & 0 & 0 & 0 & 0 \\
\hline 2 & 0 & 1 & 0 & 0 & 0 & 1 & 1 & 1 \\
\hline 3 & 1 & 0 & 1 & 0 & 0 & 0 & 1 & 1 \\
\hline 4 & 1 & 1 & 0 & 1 & 0 & 0 & 0 & 1 \\
\hline 5 & 0 & 1 & 1 & 0 & 1 & 0 & 0 & 0 \\
\hline 6 & 1 & 0 & 1 & 1 & 0 & 1 & 0 & 0 \\
\hline 7 & 1 & 1 & 0 & 1 & 1 & 0 & 1 & 0 \\
\hline 8 & 1 & 1 & 1 & 0 & 1 & 1 & 0 & 1 \\
\hline 9 & 0 & 1 & 1 & 1 & 0 & 1 & 1 & 0 \\
\hline 10 & 0 & 0 & 1 & 1 & 1 & 0 & 1 & 1 \\
\hline 11 & 0 & 0 & 0 & 1 & 1 & 1 & 0 & 1 \\
\hline 12 & 1 & 0 & 0 & 0 & 1 & 1 & 1 & 0 \\
\hline $\begin{array}{l}\text { Choice } \\
\text { Totals }\end{array}$ & tot 1 & tot 2 & tot3 & tot4 & tot5 & tot6 & tot7 & tot8 \\
\hline
\end{tabular}

consider using a $2^{\mathrm{J}}$ orthogonal fractional factorial design to assign profiles to sets, as shown in Table 1.7 above for ETS profiles. That is, I first "design" eight ETS profiles corresponding to columns labelled 1 to 8 . Now, I append a $2^{\mathrm{J}}$ orthogonal fractional factorial design to assign the profiles to 12 choice sets $(1=$ in a set; $0=$ not in a set $)$. Respondents make a choice in each choice set, and one can "count" the choices to obtain data for analysis purposes. That is, the total number of times that each profile is chosen across all 12 choice sets is an estimate of its choice frequency (choice proportion) that can be used to estimate a conditional logit model, as I now show.

I reproduce Table 1.7 in Figure 1.8, and include hypothetical best choices from 100 people who did all 12 choice sets. I use the choice totals to estimate a conditional logit model by treating the choice frequency counts as the observed choice totals in a single master choice set containing all 


\begin{tabular}{|c|c|c|c|c|c|c|c|c|}
\hline Set & Option1 & Option2 & Option3 & Option4 & Option5 & Option6 & Option7 & Option8 \\
\hline 1 & 0 & 0 & 0 & 0 & 0 & 0 & 0 & 0 \\
\hline 2 & 0 & 1 & 0 & 0 & 0 & 1 & 1 & 1 \\
\hline 3 & 1 & 0 & 1 & 0 & 0 & 0 & 1 & 1 \\
\hline 4 & 1 & 1 & 0 & 1 & 0 & 0 & 0 & 1 \\
\hline 5 & 0 & 1 & 1 & 0 & 1 & 0 & 0 & 0 \\
\hline 6 & 1 & 0 & 1 & 1 & 0 & 1 & 0 & 0 \\
\hline 7 & 1 & 1 & 0 & 1 & 1 & 0 & 1 & 0 \\
\hline 8 & 1 & 1 & 1 & 0 & 1 & 1 & 0 & 1 \\
\hline 9 & 0 & 1 & 1 & 1 & 0 & 1 & 1 & 0 \\
\hline 10 & 0 & 0 & 1 & 1 & 1 & 0 & 1 & 1 \\
\hline 11 & 0 & 0 & 0 & 1 & 1 & 1 & 0 & 1 \\
\hline 12 & 1 & 0 & 0 & 0 & 1 & 1 & 1 & 0 \\
\hline Choice Totals & tot1 & tot2 & tot3 & tot4 & tot5 & tot6 & tot7 & tot8 \\
\hline Profile & $\begin{array}{c}\text { Start } \\
\text { date }\end{array}$ & $\begin{array}{l}\text { How to } \\
\text { reven }\end{array}$ & \multicolumn{2}{|c|}{\begin{tabular}{c|c} 
se & Invest 20\% \\
in R\&D
\end{tabular}} & Exannpt & $\begin{array}{l}\text { Exempt } \\
\text { energy }\end{array}$ & $\begin{array}{c}\text { Act } \\
\text { alone }\end{array}$ & $\begin{array}{l}\text { Choice } \\
\text { coupt }\end{array}$ \\
\hline 1 & 2010 & reduce & GST & No & No & No & & \\
\hline 2 & 2010 & reduce & GST & Yes & No & Yes & & 50 \\
\hline 3 & 2010 & Snrs \& & oor & No & Yes & Yes & & \\
\hline 4 & 2010 & Snrs \& & Poor & Yes & Yes & No & No & $\boldsymbol{A}_{50}$ \\
\hline 5 & 2012 & reduce & GST & No & Yes & No & Yes & 30 \\
\hline 6 & 2012 & reduce & GST & Yes & Yes & Yes & No & 20 \\
\hline 7 & 2012 & Snrs \& & Poor & No & No & Yes & No & 25 \\
\hline 8 & 2012 & Snrs \& & & Yes & No & No & Yes & 50 \\
\hline
\end{tabular}

Figure 1.8 Hypothetical profile choices from the task in Table 1.7

eight profiles. I follow Louviere and Woodworth (1983) by estimating a conditional logit model from the choice counts using weighted least squares (WLS) regression. That is, the natural $\log$ of the choice counts is the dependent variable; the choice counts are weights that correct the non-constant error variances associated with frequency counts. The model results are in Table 1.8 .

Using a BIBD design to assign profiles to sets also produces choice totals. I now show how to do this for the same eight ETS profiles, using the Louviere et al. (2008) approach. That is, I use a BIBD to produce 14 choice sets with three options per set. Each of the eight choice options (profiles) occurs seven times and co-occurs three times with each other profile. Figure 1.9 repeats the profile design and shows the BIBD design with hypothetical best and worst choices for one person.

Figure 1.9 shows which of the eight profiles are in each choice set. For example, row one indicates that profiles 2, 3, 5 and 8 are offered. The last two columns display hypothetical best and worst choices for one person 
Table 1.8 WLS conditional logit results from Figure 1.8

\begin{tabular}{lcccc}
\hline Effect & Estimate & StdErr & T-Stat & P(T) \\
\hline Intercept & 3.208 & .076 & 42.439 & .015 \\
Start in 2010 & 0.518 & .062 & 8.403 & .075 \\
Reduce GST & -0.090 & .061 & -1.468 & .381 \\
R \& D=No & -0.065 & .059 & -1.099 & .470 \\
Transport=No & 0.297 & .060 & 4.915 & .128 \\
Energy=No & 0.385 & .061 & 6.296 & .100 \\
Act alone=No & -0.177 & .062 & -2.881 & .203 \\
\hline
\end{tabular}

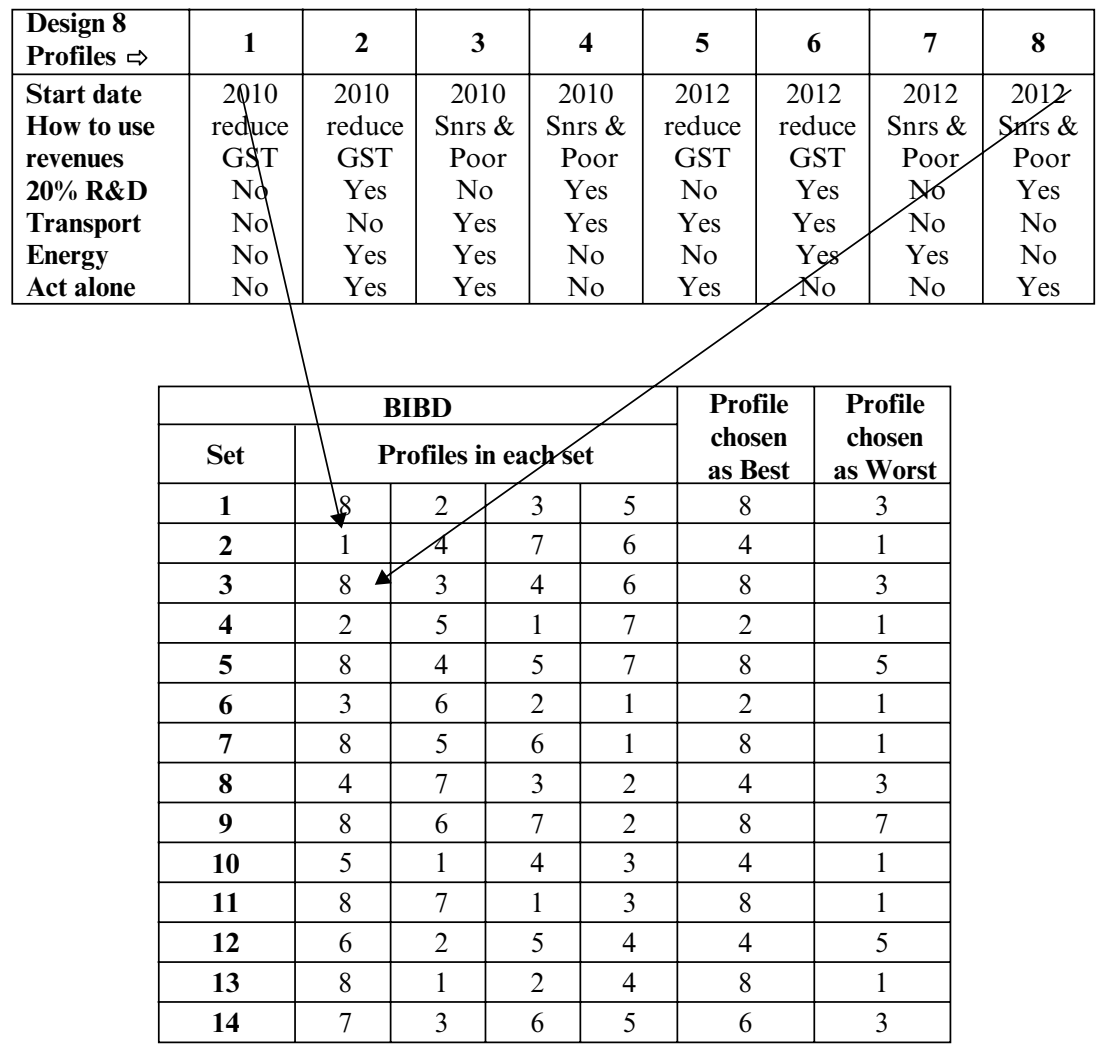

Figure 1.9 Assigning profiles to sets with a suitable BIBD and hypothetical choices 
Table 1.9 Best and Worst choice counts and differences for profiles

\begin{tabular}{lccc}
\hline Profile & Best & Worst & B-W \\
\hline 1 & 0 & 7 & -7 \\
2 & 2 & 0 & 2 \\
3 & 0 & 4 & -4 \\
4 & 4 & 0 & 4 \\
5 & 0 & 2 & -2 \\
6 & 1 & 0 & 1 \\
7 & 0 & 1 & -1 \\
8 & 7 & 0 & 7 \\
\hline
\end{tabular}

for each choice set. It is important to note that the choices refer to the eight options (i.e., numbers 1 to 8). I calculate choice (frequency) counts and BWS difference scores for the eight options, as shown in Table 1.9. Here the counts represent a perfectly consistent choice process whereby the hypothetical person has a rank ordering of the eight options and always chooses exactly in that order. Thus, there is no error.

I now repeat the same exercise, giving the person some choice "error" by assigning a "true" utility to each of the eight options as follows: (1) I divided the BWS difference scores by 6 , and (2) added a uniform random error to each occurrence of an option across the 14 choice sets by using the RAND() procedure in Excel to generate random numbers between 0 and 1 for each option in each choice set. Random numbers $>0.5$ were added to the true utilities, and numbers $<0.5$ were subtracted from the true utilities. I calculated the implied rank of each option in each choice set in two ways: (1) assuming I had sufficient best and worst choices for a full ranking (i.e., ranks 1 to 4), and (2) assuming I only had best and worst choices, or three implied ranks with the two middle ranks tied.

I coded the resulting three ranks as $1=1,2=0$ and $3=-1$, and (a) calculated the mean values of each attribute level in the design (BWMean), and (b) estimated an OLS regression with the coded ranks as the dependent variable (BWS-OLS). I then estimated an exploded logit model for three (ROL3) and four ranks (ROL4). Finally, I used the Louviere et al. (2008) approach to calculate the choice counts expected for each option in each choice set by assuming that (a) the ranks are used to predict the expected counts in all possible non-empty choice sets, and (b) the person chooses consistently with the implied ranking for the three or four ranks in the simulation. Calculation and model estimation results are in Table 1.10, with a graphical comparison of model estimates and the simple BWMean calculation shown in Figure 1.10. 
Table 1.10 Calculations/estimates from simulated Best and Worst choices

\begin{tabular}{lrrrrr}
\hline \multirow{2}{*}{$\begin{array}{l}\text { Attribute } \\
\text { Levels }\end{array}$} & \multicolumn{5}{c}{ Calculation and Estimation Results } \\
\cline { 2 - 6 } & BWMean & BWS-OLS & ROL4 & ROL3 & WLS \\
\hline 2010 & 0.0714 & 0.0625 & 0.1839 & 0.2138 & 0.1393 \\
2012 & -0.0357 & -0.0625 & -0.1839 & -0.2138 & -0.1393 \\
Snrs \& Poor & -0.1071 & -0.1563 & -0.4139 & -0.4852 & -0.2596 \\
GST & 0.1429 & 0.1563 & 0.4139 & 0.4852 & 0.2596 \\
R\&D Yes & 0.3929 & 0.4479 & 0.9897 & 1.1160 & 0.5550 \\
R\&D No & -0.3571 & -0.4479 & -0.9897 & -1.116 & -0.555 \\
Transp Yes & 0.0000 & -0.0104 & -0.0823 & -0.0740 & -0.0126 \\
Transp No & 0.0357 & 0.0104 & 0.0823 & 0.074 & 0.0126 \\
Energy Yes & 0.1071 & 0.1042 & 0.0369 & 0.4273 & -0.0843 \\
Energy No & -0.0714 & -0.1042 & -0.0369 & -0.4273 & 0.0843 \\
ActAlone Yes & 0.1071 & 0.1042 & 0.4593 & 0.2651 & 0.1345 \\
Act Alone No & -0.0714 & -0.1042 & -0.4593 & -0.2651 & -0.1345 \\
\hline
\end{tabular}

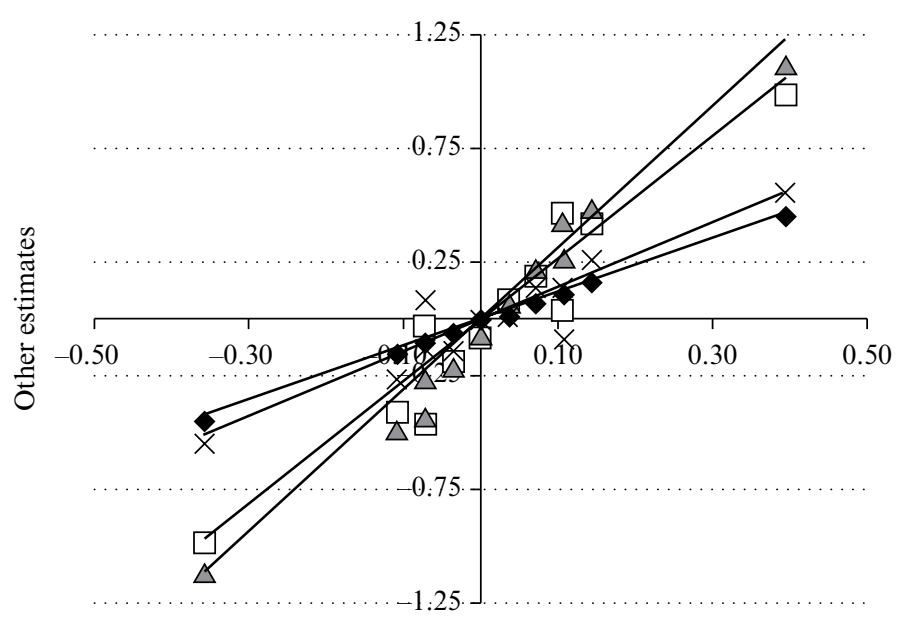

$$
\begin{aligned}
& y=1.1825 x \\
& R^{2}=0.9885 \\
& y=2.699 x \\
& R^{2}=0.92
\end{aligned}
$$

Mean BWS scores (Best minus Worst)

$\mathrm{y}=1.4256 \mathrm{x}$
$\mathrm{R}^{2}=0.8575$

Figure 1.10 Mean BW differences compared with other estimates

The graphical results clearly suggest that all calculation and estimation methods produce estimates proportional to one another, which has generally held for virtually all empirical cases I've worked on in the past several years. The takeaway is that simple BWS differences scores typically are a 
Table 1.11 Attributes and associated levels in flight DCE example

\begin{tabular}{ll}
\hline Attributes & Levels \\
\hline Return air fare & $\$ 350, \$ 450, \$ 550, \$ 650$ \\
Number of stops & $0,1,2,3$ \\
Total travel time & $4,5,6,7$ hours \\
Type of airplane & B-737, B-717 \\
In-flight hot meal & No, Yes \\
In-flight beverage & No, Yes \\
Airline & Southwest, Northwest \\
\hline
\end{tabular}

\begin{tabular}{|l|c|c|c|c|}
\hline Information about flights & Flight A & Flight B & Flight C & Flight D \\
\hline Return air fare & $\$ 550$ & $\$ 350$ & $\$ 650$ & $\$ 450$ \\
\hline Number of stops & 2 & 3 & 0 & 1 \\
\hline Total travel time & 5 & 7 & 6 & 4 \\
\hline Type of airplane & B-737 & B-717 & B-737 & B-717 \\
\hline In-flight hot meal & No & Yes & Yes & No \\
\hline In-flight beverage & Yes & No & Yes & No \\
\hline Airline & Southwest & Southwest & Northwest & Northwest \\
\hline 1. Which flight do you prefer most? & $\square$ & $\square$ & $\square$ & $\square$ \\
\hline 2. Which flight do you prefer least? & $\square$ & $\square$ & $\square$ & $\square$ \\
\hline $\begin{array}{l}\text { 3. Which flight do you prefer 2nd most? } \\
\text { 4. Check the box to the right if you actually would choose not to fly if these were your only } \\
\text { travel options } \Rightarrow \square\end{array} \square$ & $\square$ & $\square$ & $\square$ & $\square$ \\
\hline
\end{tabular}

Figure 1.11 Example choice set/task from flight DCE

reasonably good first approximation to the latent utilities and always can be calculated for a single person if a DCE is properly designed. Now I use other empirical examples to illustrate the ideas.

\subsection{Cross-country flight choices by 12 short course students}

When I first began to explore the BWS approach to modeling individuals, I designed a DCE and administered it to 12 students to see if they could provide best and worst choices. The DCE involved choices of crosscountry airline flights in the USA, with the attributes and levels in Table 1.11. I constructed the DCE using the Street and Burgess (2007) design approach. An example choice set and associated choice task questions are shown in Figure 1.11. Each student completed all 16 choice sets generated by the DCE design. 
Table 1.12 Estimation results for cross-country flight choices for 12 students

\begin{tabular}{llrl}
\hline WLS Estimates & & & \\
\hline Effect & $\mathrm{N}$ & Estimate & StdDev \\
\hline$\$ 350$ & 12 & 0.4699 & 0.197 \\
$\$ 450$ & 12 & 0.3108 & 0.1744 \\
$\$ 550$ & 12 & -0.1573 & 0.1207 \\
$\$ 650$ & 12 & -0.6235 & 0.2444 \\
0 stops & 12 & 0.1920 & 0.2308 \\
1 stop & 12 & 0.1609 & 0.3014 \\
2 stops & 12 & -0.0488 & 0.1720 \\
3 stops & 12 & -0.3042 & 0.3319 \\
4 hours & 12 & 0.4136 & 0.1963 \\
5 hours & 12 & -0.2967 & 0.1509 \\
6 hours & 12 & -0.5594 & 0.1577 \\
7 hours & 12 & 0.0101 & 0.2995 \\
B717 & 12 & -0.0101 & 0.0611 \\
B737 & 12 & 0.0168 & 0.0611 \\
Meal & 12 & -0.0168 & 0.0541 \\
Snack & 12 & 0.0153 & 0.0541 \\
NWA & 12 & -0.0153 & 0.0613 \\
SWA & 12 & & 0.0613 \\
\hline
\end{tabular}

The Best-Worst choice task in Figure 1.11 yields a full ranking of options in each choice set. I expanded the rankings using the Louviere et al. (2008) approach to get an expected number of choices (counts) associated with each option in each choice set. I used the natural log of the expected choice counts as the dependent variable in a WLS regression; the weights are the implied choice counts (to correct for non-constant error variances). The WLS result is a first step in an iteratively reweighted least squares approach (Green 1984) to obtain the maximum likelihood estimates of a conditional logit model, as discussed by Louviere and Woodworth (1983). Estimation results for the 12 students are in Table 1.12; the results are analogous to random parameters, but I made no distributional assumption to obtain the results. I graph the WLS results for three attributes in Figure 1.12.

The graphical results suggest considerable preference homogeneity for the 12 students. So, not surprisingly, if I estimate an aggregate conditional logit model from the choices, the pseudo R-square for that model is 0.56 , confirming what the graphs reveal. In turn, this suggests that we can use the Louviere et al. (2008) expansion approach and WLS regression 

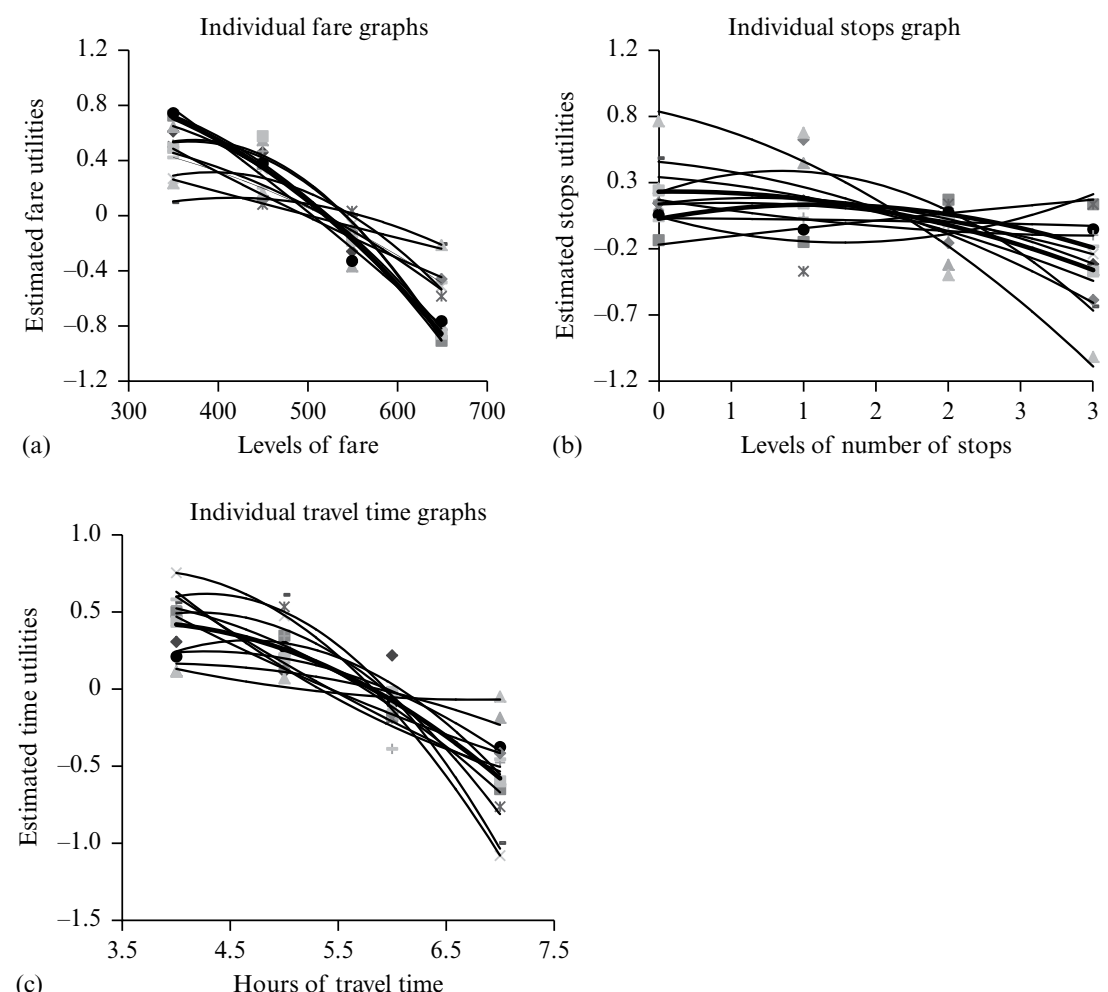

Figure 1.12 Individual utility curves for three attributes in flight DCE

estimation to obtain conditional logit model estimates for each person. It is worth noting that the WLS regression includes dummy variables for C-1 of the $\mathrm{C}$ total choice sets to capture the choice set denominators associated with linearizing conditional logit models (Louviere and Woodworth 1983).

\subsection{A second group: 20 students}

This example involves a similar task and design as the first example. I first display the individual Best choice counts for each student in Table 1.13. One italic column represents the only person who did not exhibit a perfect classifier. That is, all other students exhibit choice totals for attribute levels that contain zero choices or a maximum number of choices (16). For example, several people chose flight options with the lowest fare every time it was available. Typically, Street and Burgess (2007) DCE designs 


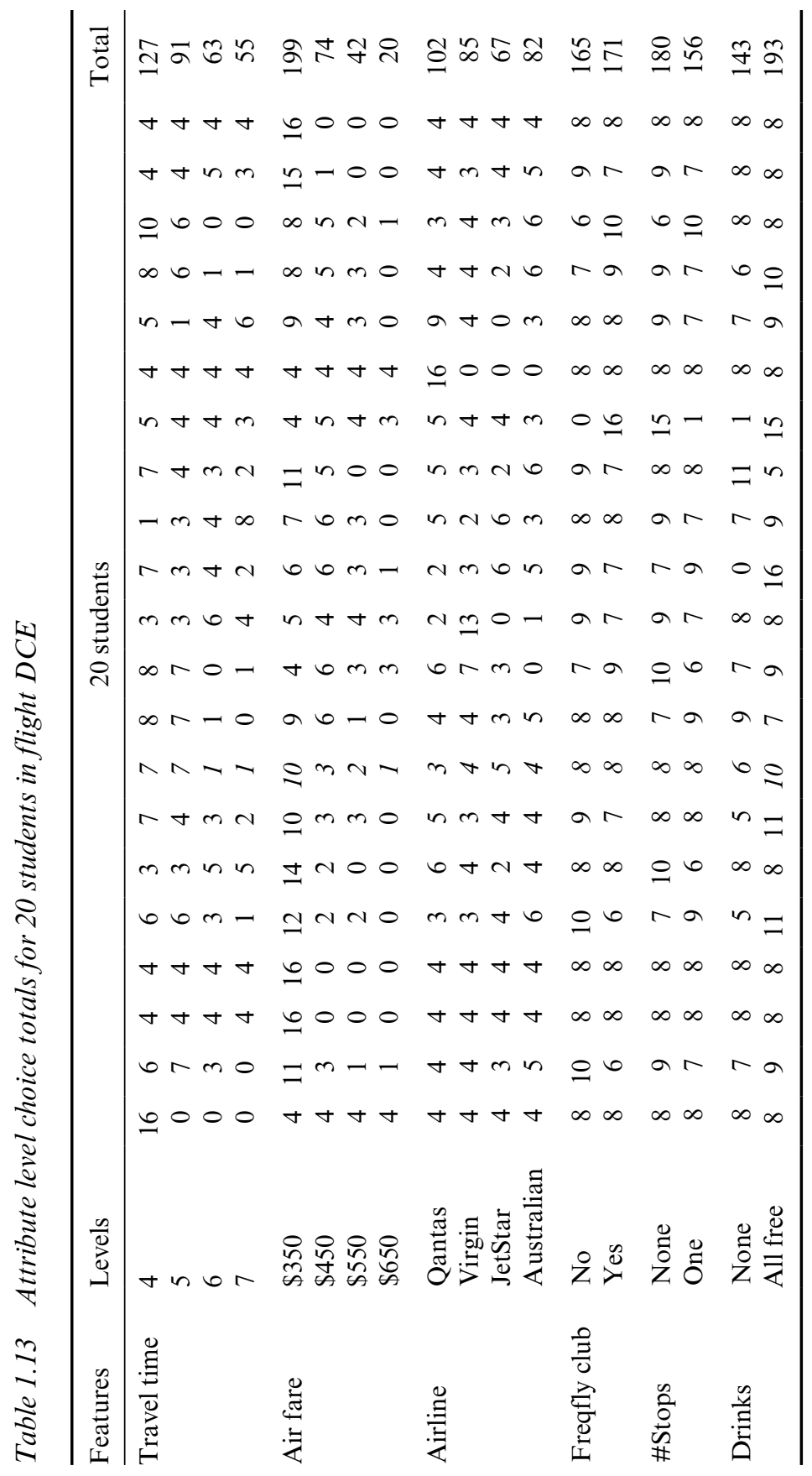




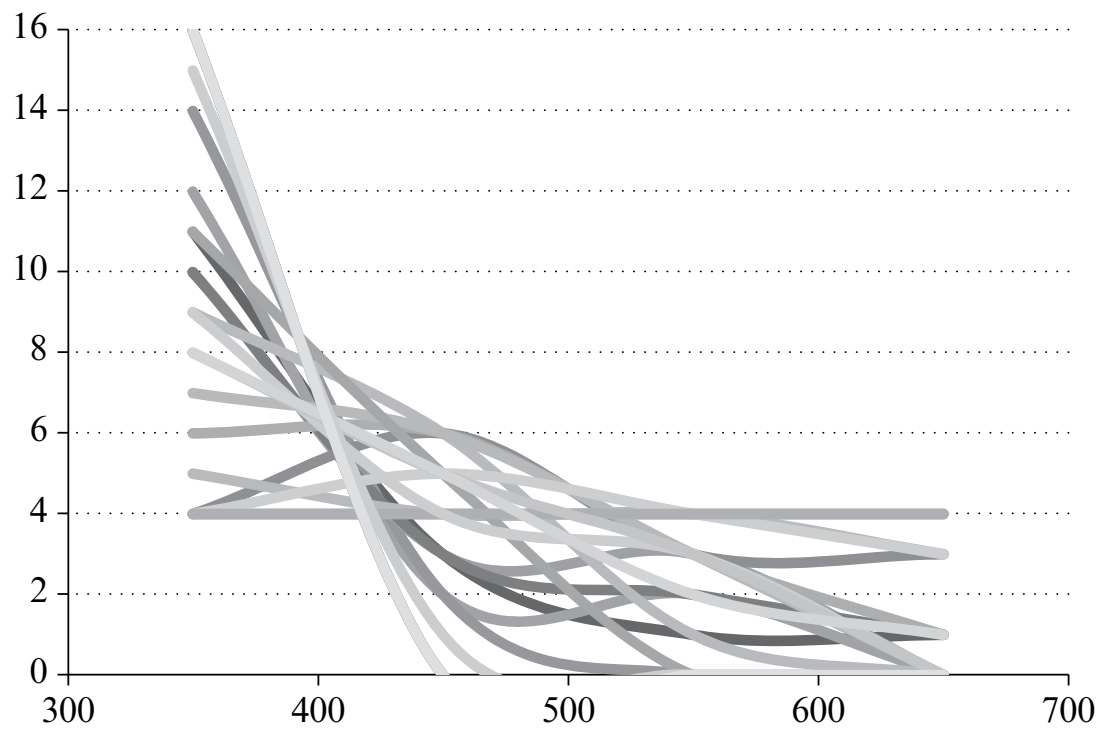

Figure 1.13 Individual responses to fare levels in second flight DCE

generate choice sets where each level of every attribute occurs, making it easy for people who want to choose on one attribute level to do so. Table 1.13 shows that many people made choices in this way. I examined several prior DCE datasets using Street and Burgess (2007) designs and found this phenomenon in each. In turn, this suggests we may want to reconsider how we design DCEs and/or which design approaches consistently give externally valid predictions of real choices. I graph the relationship between levels of fare and choice counts for each student in Figure 1.13, which suggests more heterogeneity than the previous example.

Table 1.14 summarizes the WLS model estimation results for the 20 students.

The takeaway from the second example is that I again can estimate WLS models for each person. Moreover, if I design a DCE properly, I also obtain choice count information about each attribute level for each person. This information lets me "see" who is doing what that can be used to inform modeling. One also can use the choice counts on their own to identify similar individuals using a variety of cluster analytic, latent class of other taxonomic procedures. I typically (but not always) find that when I cluster individuals based on their choice counts the resulting clusters produce very large likelihood differences compared to a single, one-sizefits-all conditional logit model. 
Table 1.14 Sample statistics for 20 sets of WLS model estimates

\begin{tabular}{lrrrrr}
\hline Effect & $\mathrm{N}$ & Mean & StdErr & StdDev & T-Stat \\
\hline Time4 & 20 & 0.208 & 0.069 & 0.318 & 3.140 \\
Time5 & 20 & 0.113 & 0.039 & 0.178 & 2.910 \\
Time6 & 20 & -0.076 & 0.032 & 0.147 & -2.360 \\
Time7 & 20 & -0.255 & 0.075 & 0.342 & -3.420 \\
Fare\$350 & 20 & 0.534 & 0.076 & 0.347 & 7.060 \\
Fare\$450 & 20 & 0.166 & 0.059 & 0.272 & 2.790 \\
Fare\$550 & 20 & -0.156 & 0.033 & 0.150 & -4.760 \\
Fare\$650 & 20 & -0.543 & 0.085 & 0.391 & -6.370 \\
Qantas & 20 & 0.148 & 0.060 & 0.273 & 2.490 \\
Virgin & 20 & 0.002 & 0.075 & 0.345 & 0.020 \\
JetStar & 20 & -0.111 & 0.078 & 0.358 & -1.420 \\
AustAir & 20 & -0.039 & 0.055 & 0.253 & -0.710 \\
Frequent Flyer_no & 20 & -0.027 & 0.019 & 0.088 & -1.400 \\
Frequent Flyer_yes & 20 & 0.027 & 0.019 & 0.088 & 1.400 \\
Stops_0 & 20 & 0.022 & 0.014 & 0.063 & 1.600 \\
Stops_3 & 20 & -0.022 & 0.014 & 0.063 & -1.600 \\
Drinks_no & 20 & -0.089 & 0.033 & 0.152 & -2.670 \\
Drinks_yes & 20 & 0.089 & 0.033 & 0.152 & 2.670 \\
\hline
\end{tabular}

\subsection{How about a larger sample with real consumers?}

Now, I use the same ideas discussed above to estimate ILMs for typical consumer samples. I do this by using the extra rank information from the best and worst choices of $\mathbf{J}$ options in each set to expand the most and least choices. As before, I do this by calculating the implied choices using the Louviere et al. (2008) approach to anticipate the $2^{\mathrm{J}}$ choice totals/counts for each of the $\mathrm{J}$ options in a choice set for all $2^{\mathrm{J}}-1$ nonempty choice sets. The example involves choices among delivered pizza options described by nine attributes: Brand (4) $\times$ Price $(3) \times$ Delivery Time (4) $\times$ Crust (2) $\times$ Free Drink (2) $\times$ Toppings $(2) \times$ Free Desert (2) $\times$ Free Delivery (2) $\times$ Free Salad (2). I first constructed 16 pizza profiles (choice options) using an orthogonal main effect design, and then I used the Louviere et al. (2008) BIBD approach to assign the 16 profiles to 20 choice sets. Each choice set has four pizza options. The sample is 501 people who purchase delivered pizzas at least once every three months, randomly drawn from an online panel in Australia, but I only analyse the first 50 people in the datafile. The data are the first wave of a three-year 


\begin{tabular}{|c|c|c|c|c|}
\hline \multicolumn{5}{|c|}{ Lunch/Dinner/Snack/other opportunity to consider ordering a large pizza: } \\
\hline Delivered pizza features & Pizza A & Pizza B & Pizza C & Pizza D \\
\hline Brand & Brand A & Brand B & Brand C & Brand D \\
\hline Topping & Veggie Supreme & Pepperoni & Hawalian & Pepperoni \\
\hline Crust & Regular Crust & Thick Crust & Regular Crust & Thick Crust \\
\hline Drink & 2 Liter Bottle & 2 Liter Bottle & 2 Liter Bottle & 1 Liter Bottle \\
\hline Delivery Time & 30 Minutes & 35 Minutes & 35 Minutes & 25 Minutes \\
\hline Price & $\mathbf{\$ 8 . 9 0}$ & $\$ 12.90$ & $\$ 8.99$ & $\$ 14.90$ \\
\hline My first choice pizza is ( & $\sqrt{6}$ & Q & & 0 \\
\hline My last choice pizza is ( $\boldsymbol{V}$ one): & e & 0 & $\sqrt{6}$ & 0 \\
\hline
\end{tabular}

Tell us how you would order on this occasion. I would be willing to ( $\sqrt{ }$ one):

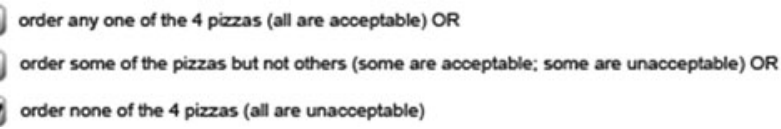

Figure 1.14 Example choice set/task from the pizza DCE

study of stability of DCE choices over time. I return to preference stability later.

An example of the DCE task is shown in Figure 1.14 above: respondents made most and least preferred choices in each set, and indicated if they would purchase their most preferred option if they could only pick from the four pizzas in each set. I analyse only the most and least preferred choices in this example.

I compare the sample aggregate maximum likelihood conditional logit model estimation results with the mean of the model parameters and associated statistics from the ILM estimations in Table 1.15, and compare them graphically in Figure 1.15.

The results indicate both approaches yield proportional estimates, but the estimates have different scales due to error variability differences in each estimation approach. This implies one must rescale the WLS estimates to predict accurately. I return to this issue later in the chapter.

\subsection{Sequential choice processes}

Asking people to choose Best, then Worst, then Next Best (or any other variant) implies a sequential choice process. Thus, it is important to recognize that even if one asks more questions to obtain a full ranking, this does not imply that a person in fact ranks 1 , then 2 , then 3 , etc. As earlier 
Table 1.15 Descriptive statistics for individuals in pizza DCE

\begin{tabular}{|c|c|c|c|c|c|c|}
\hline \multirow[t]{2}{*}{ Effect } & \multicolumn{3}{|c|}{ WLS } & \multicolumn{3}{|c|}{ MaxL } \\
\hline & Mean & $\mathrm{SE}$ & T-stat & Est & SE & Wald \\
\hline $\mathrm{ASC1}$ & -0.053 & 0.052 & -1.020 & -0.196 & 0.286 & 0.469 \\
\hline ASC2 & 0.030 & 0.043 & 0.711 & -0.019 & 0.180 & 0.011 \\
\hline ASC3 & 0.007 & 0.039 & 0.190 & -0.001 & 0.154 & 0.000 \\
\hline ASC4 & 0.025 & 0.033 & 0.749 & 0.000 & & \\
\hline Pizza Hut & 0.025 & 0.057 & 0.432 & 0.112 & 0.146 & 0.597 \\
\hline Domino's & -0.054 & 0.030 & -1.820 & -0.227 & 0.120 & 3.533 \\
\hline Eagle Boy & 0.002 & 0.038 & 0.057 & 0.118 & 0.094 & 1.578 \\
\hline Pizza Hav & 0.027 & & & -0.004 & & \\
\hline$\$ 12$ & 0.298 & 0.038 & 7.815 & 0.822 & 0.079 & 108.957 \\
\hline$\$ 14$ & 0.126 & 0.023 & 5.446 & 0.279 & 0.082 & 11.415 \\
\hline$\$ 16$ & -0.070 & 0.022 & -3.160 & -0.201 & 0.087 & 5.391 \\
\hline$\$ 18$ & -0.354 & & & -0.900 & & \\
\hline 10 mins & 0.082 & 0.024 & 3.432 & 0.092 & 0.110 & 0.691 \\
\hline 20 mins & 0.071 & 0.020 & 3.523 & 0.224 & 0.078 & 8.338 \\
\hline 30 mins & -0.014 & 0.020 & -0.683 & -0.038 & 0.084 & 0.205 \\
\hline 40 mins & -0.139 & & & -0.278 & & \\
\hline 1 topping & -0.169 & 0.026 & -6.411 & -0.463 & 0.054 & 74.745 \\
\hline 3 toppings & 0.169 & & & 0.463 & & \\
\hline no free deliv & -0.145 & 0.018 & -7.947 & -0.476 & 0.053 & 80.183 \\
\hline free delivery & 0.145 & & & 0.476 & & \\
\hline regular crust & 0.002 & 0.023 & 0.087 & 0.011 & 0.053 & 0.045 \\
\hline thin crust & -0.002 & & & -0.011 & & \\
\hline no free dess & -0.120 & 0.016 & -7.287 & -0.307 & 0.052 & 34.449 \\
\hline free desert & 0.120 & & & 0.307 & & \\
\hline no free drink & -0.107 & 0.015 & -7.380 & -0.313 & 0.052 & 35.970 \\
\hline free drink & 0.107 & & & 0.313 & & \\
\hline no free salad & -0.085 & 0.019 & -4.383 & -0.201 & 0.053 & 15.814 \\
\hline free salad & 0.085 & & & 0.201 & & \\
\hline
\end{tabular}

noted, people can make these choices in several ways; ideally one wants estimated models to reflect the "correct" sequence. Marley and Louviere (2005) discuss sequential process models, and Lancsar and Louviere (2008) consider one of them. Empirical experience suggests one can get much better statistical fits by estimating models that more closely reflect sequential choices. 


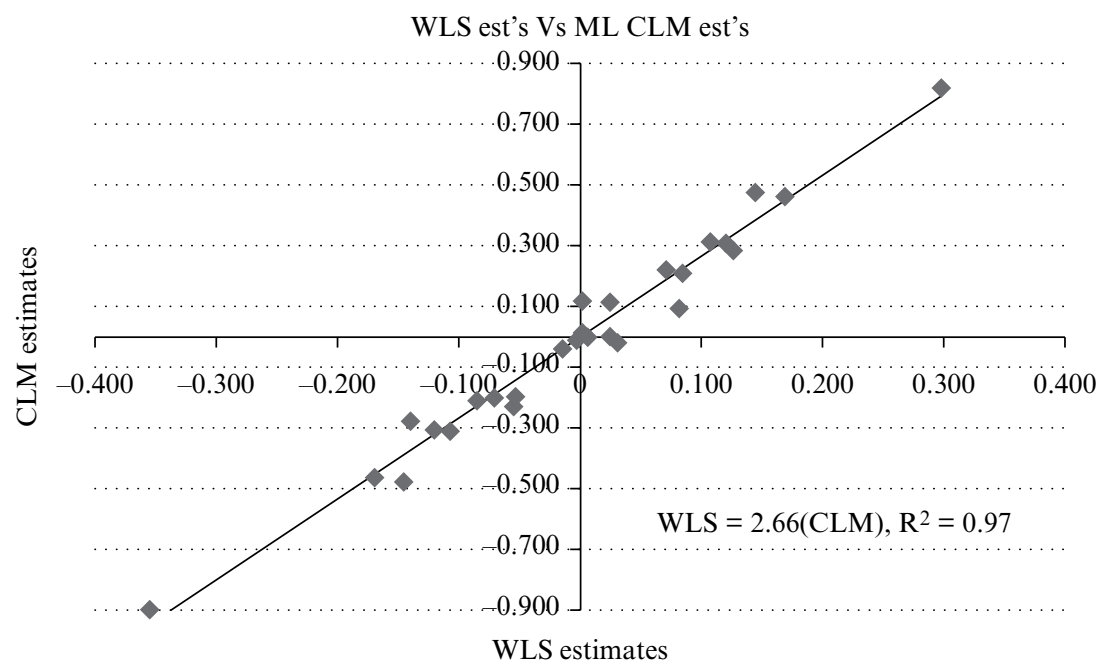

Figure 1.15 Comparison of WLS and MaxL estimates from pizza DCE

Now I give an example of Sequential BWS (SBW) for mobile phone choices collected from two random samples drawn from an online panel in December 2007 (Wave 1, $\mathrm{n}=468$ ) and February 2008 (Wave 2, $\mathrm{n}=405$ ). The DCE was based on a Street and Burgess (2007) design that produced 32 choice sets with four options in each. Respondents completed all 32 choice sets, reporting their most and least preferred choices in each set as well as if they would buy their most preferred phone option if available; a typical choice set is shown in Figure 1.16.

We asked a second round of most and least choices to get a full ranking in each set. This suggests comparing an ordered logit model with a sequential choice model. Ordered logit models assume a person ranks the choice options in order (1, then 2 , then 3 , etc); one models the probability that the ranking is $1>2>3>4$. In contrast, a sequential choice model assumes a person chooses sequentially, such as choose most, then least, then next most, etc (ie, maybe 1,2,3,4; maybe 2,3,1,4). One models the probability of a particular sequence of choices. Below I compare the two models, and graphically illustrate them in Figure 1.17.

Probability that the phones are ranked $\mathrm{A}>\mathrm{B}>\mathrm{C}>\mathrm{D}$

$=$ Prob[choosing Phone A as "best" from \{Phone A, Phone B, Phone C, Phone D $\}] \times$ Prob[choosing Phone B as "best" from \{Phone B, Phone C, Phone D $\}] \times$ Prob[choosing Phone $\mathrm{C}$ as "best" from \{Phone C, Phone D $\}$ ] 
Review Instructions

\begin{tabular}{|c|c|c|c|c|}
\hline ull Attribute Information & Phone A & Phone B & Phone C & Phone D \\
\hline \multicolumn{5}{|l|}{ Phone Style } \\
\hline & Clam or flip phone & $\begin{array}{l}\text { Candy Bar or } \\
\text { straight phone }\end{array}$ & Swivel flip & $\begin{array}{l}\text { PDA phone with } \\
\text { touch screen } \\
\text { input }\end{array}$ \\
\hline$\underline{\text { Handset Brand }}$ & Motorola & Nokia & Samsung & Sony Ericson \\
\hline Price & $\$ 49.00$ & $\$ 199.00$ & $\$ 249.00$ & $\$ 129.00$ \\
\hline Built-in Camera & No camera & $\begin{array}{l}5 \text { megapixel } \\
\text { camera }\end{array}$ & $\begin{array}{l}2 \text { megapixel } \\
\text { camera }\end{array}$ & $\begin{array}{l}3 \text { megapixel } \\
\text { camera }\end{array}$ \\
\hline$\underline{\text { Wireless Connectivity }}$ & $\begin{array}{l}\text { No Bluetooth or } \\
\text { WiFi connectivity } \\
\text { No video recordings }\end{array}$ & $\begin{array}{l}\text { Bluetooth and WiFi } \\
\text { connectivity }\end{array}$ & WiFi connectivity & $\begin{array}{l}\text { Bluetooth } \\
\text { connectivity }\end{array}$ \\
\hline Video Capability & & $\begin{array}{l}\text { Video recording } \\
\text { (up to } 1 \text { hour) }\end{array}$ & $\begin{array}{l}\text { Video recording } \\
\text { (more than } 1 \\
\text { hour) }\end{array}$ & $\begin{array}{l}\text { Video recording } \\
\text { (up to } 15 \\
\text { minutes) }\end{array}$ \\
\hline Internet Capability & Internet Access & Internet Access & $\begin{array}{c}\text { No Internet } \\
\text { Access }\end{array}$ & $\begin{array}{c}\text { No Internet } \\
\text { Access }\end{array}$ \\
\hline$\underline{\text { Music Capability }}$ & $\begin{array}{l}\text { No music } \\
\text { capability }\end{array}$ & $\begin{array}{l}\text { MP3 Music Player } \\
\text { only }\end{array}$ & FM Radio only & $\begin{array}{l}\text { MP3 Music Player } \\
\text { and FM Radio }\end{array}$ \\
\hline Handset Memory & $\begin{array}{l}64 \mathrm{MB} \text { built-in } \\
\text { memory }\end{array}$ & $\begin{array}{l}2 \text { GB built-in } \\
\text { memory }\end{array}$ & $\begin{array}{l}512 \text { MB built-in } \\
\text { memory }\end{array}$ & $\begin{array}{l}4 \text { GB built-in } \\
\text { memory }\end{array}$ \\
\hline
\end{tabular}

Figure 1.16 Typical choice set for mobile phone DCE

(1)

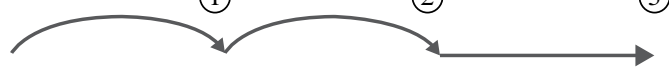

ROL

$W$

$X$

Y

Rank-order of preference

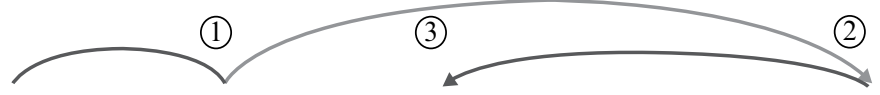

SBW

$\begin{array}{lllll}W & X & Y & Z\end{array}$

Figure 1.17 Graphical comparison of straight ranking versus sequential choice 
Probability that the phones are ranked $\mathrm{A}>\mathrm{B}>\mathrm{C}>\mathrm{D}$

$=$ Prob[choosing Phone A as "best" from $\{$ Phone A, Phone B, Phone C, Phone D $\}] \times$ Prob[choosing Phone B as "worst" from $\{$ Phone B, Phone C, Phone D $\}] \times$ Prob[choosing Phone $\mathrm{C}$ as "best" from $\{$ Phone C, Phone D $\}$ ]

We compared an aggregate one-size-fits-all ordered logit model with sequential BW ILMs on the mobile phone data (see also Marley and Pihlens 2012). The ordered logit model is nested under the ILMs (a restriction), so we used a Likelihood Ratio (LR) test to compare them. The aggregate ordered logit model fits poorly (pseudo- $\mathrm{r}^{2}=0.03$ ), likely due to considerable heterogeneity. The ILMs fit well $\left(\mathrm{r}^{2}=0.48\right)$ and outperform the ordered logit model despite many more parameters $(\mathrm{df}=14,415-31$ $=14,384)$. We asked respondents to first choose the best in each set, and then choose the worst from the rest, and repeated these questions until only one unchosen option remained.

We used a sequential Best-Worst (SBW) model to estimate the ILMs (Marley and Louviere, 2005; Lancsar and Louviere, 2008) as it reflects the sequential best and worst choice process. That is, choose best from the whole set, then the worst from the reduced set, etc. We constrained the worst utilities to be symmetric to the best utilities, but this is not necessary in general. Indeed, one can well imagine that in certain choice contexts, they would not be symmetric and/or the scale of the utilities can differ (e.g., worst choices may be easier/harder than best choices). This begs the empirical question of how good is the SBW model? The aggregate SBW fit the data poorly, although it was slightly better than the ordered logit model (pseudo- $\mathrm{r}^{2}=0.03$ ). The SBW ILMs fit the data very well (pseudo- ${ }^{2}$ $=0.58)$, better than the aggregate $\mathrm{SBW}(\mathrm{LR}=52483.40, \mathrm{df}=14,384)$.

Here are some ILMs takeaways: (1) It is easy to design/administer DCEs to estimate ILMs from online panels; experience suggests such DCEs can handle fairly many attributes and levels. For example, Sawtooth Software challenged CenSoC to a model-off in 2010. Sawtooth used their HB approach to estimate random coefficient models and predict choices in holdout sets. CenSoC used an ILM approach. One of the two modeling tests involved estimation of 26 utility parameters per person, large by DCE standards. (2) CenSoC teams have estimated ILMs for many thousands of people, and have been able to estimate models for each person. (3) ILM results appear to be robust to several estimation methods and can identify people who seem to use lexicographic or similar non-additive decision rules. (4) ILMs can do what random coefficient models do, and can decompose variance associated with attribute levels within and between people and can measure the error variability for each person. (5) If one 
uses a common ILM design for all individuals, one can avoid confounding differences in preferences and error variances across people with differences in designs. (6) ILMs avoid assumptions about sample distributions of model parameters and/or scales associated with random parameter models and more flexible forms like G-MNL (Fiebig et al. 2010). As I write this, we are preparing a concept/methods paper for a book, with several papers being prepared to submit to journals. One can download current papers and results (e.g. Frischknecht et al. (2011a, 2011b) from http://www.censoc.uts.edu.au/researchoutput/paper.html.

\section{ERROR VARIANCE DIFFERENCES WITHIN AND BETWEEN PEOPLE}

I've studied scale differences since the first Invitational Choice Symposium at Banff, Alberta, Canada in 1990 (e.g. Swait and Louviere 1993). My interest in ILMs complements my interest in understanding and modeling error variance (scale) differences. That is, I want to (1) separate individuallevel and sample-level error variances; (2) decompose individual-level error variances by attribute, choice set, order and other design-related differences (context, frame, etc.); and (3) distinguish differences in preferences from differences in scale.

At this time one cannot separate error variance and model misspecification (choice process and/or decision rule), as more general and flexible design and modeling approaches are required. I now briefly discuss using DCEs and ILMs to study variance differences. I return to the flight choice DCE completed by 20 students ( 32 choice tasks for four options based on a $3^{3} \times 2^{3}$ ) where we asked several best and worst choices in each set to obtain a full ranking.

As discussed earlier, I estimated WLS models for each person from the full ranking in each choice set by expanding the ranks to produce the implied (expected) choices if each person chose consistently with their rank order in all possible non-empty sets $\left(2^{\mathrm{J}}-1\right.$ sets). I used the estimated WLS models to calculate the mean of the squared residuals (MSR) from the model predictions for each person for each option in each choice set. The MSRs capture variability in choices within and between people plus specification error. Random utility theory predicts that model estimates will be inversely related to error variance: as error variance goes to zero, estimates go to infinity, and as error variances go to infinity, model estimates go to zero. I thank Michael Keane for suggesting that I test this by graphing each person's estimates against their MSR. Figure 1.18 graphs each person's model estimates against their MSR for fare. This shows 


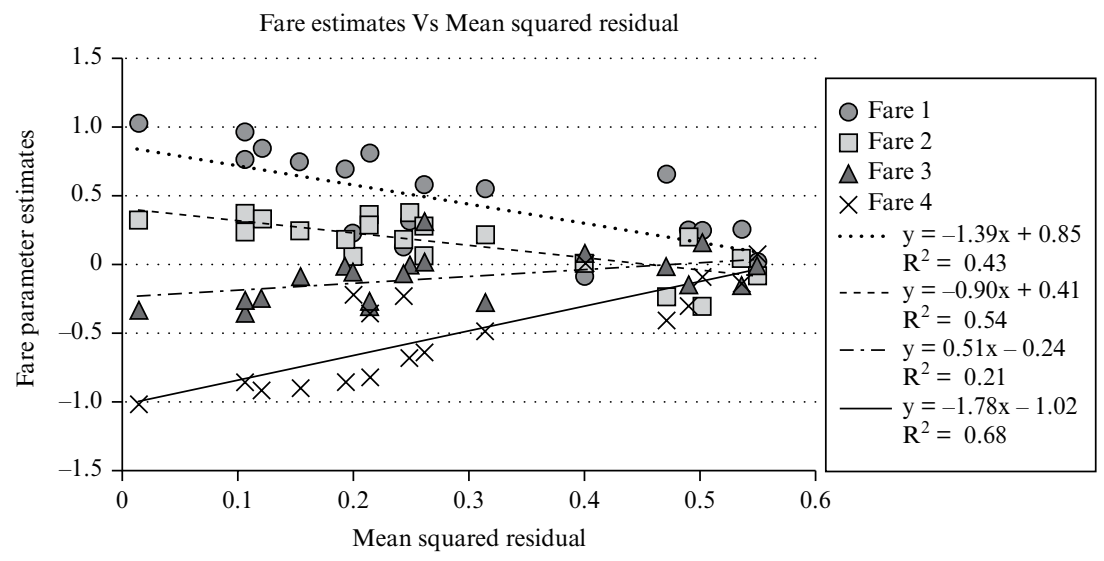

Figure 1.18 Fare estimates versus MSRs for 20 people

that as a person's MSR increases, the associated parameters for fare go to zero. It also shows that a large proportion of the variability in the fare parameters is due to differences in individual MSRs. In turn, this suggests that more consistent people exhibit higher fare sensitivity and less consistent people exhibit less fare sensitivity (of course, some MSR variability is model misspecification). The graph highlights that one must separate error variance (scale) and model parameters, or risk incorrect inferences about policy implications for things like willingness to pay. That is, one does not want to tell policy makers that a group of people who make choices more consistently than others are willing to pay more. Figure 1.19 displays two more graphs for larger samples of consumers for DCEs involving fruit juice drinks and delivered pizzas. Both graphs tell the same story, so Figure 1.18 is not an isolated example.

One can view the results in Figures 1.18 and 1.19 in another way; that is, one can treat each person's MSR as a covariate and interact it with each attribute level in a conditional logit model (across people). That is, after estimating MSRs for each person, one can use the MSRs as predictors in a second-stage (sequential) conditional logit model by interacting MSRs with ASCs and/or attribute levels. I show one example for an airline flight DCE with approximately 400 consumers randomly drawn from an online panel, subject to having made an airline trip in the past three years and/or intending to do so in the next 12 months.

I estimate a sample conditional logit model from only most choices, and then a second model with each person's MSR interacted with attribute levels. Results are in Tables 1.16 and 1.17.

The interaction results indicate that most MSR interactions with 

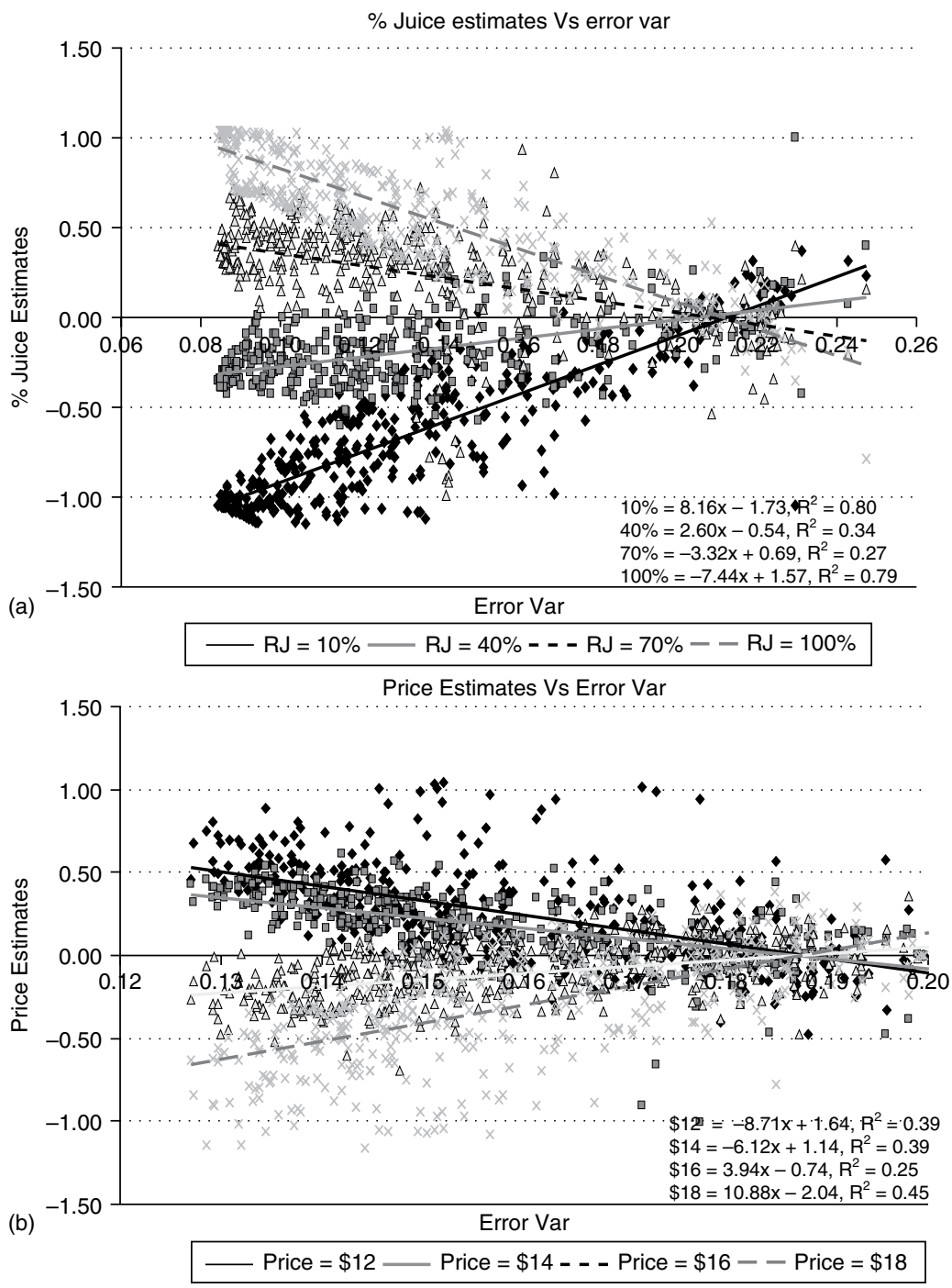

Figure 1.19 ILM estimates versus MSR for larger samples

attribute levels were highly significant; they also are consistent with the pattern of converging straight lines in the graphs of MSR versus model parameters above. This provides one way to decompose error variance and parameter sensitivity, but smarter people than me should be able to do a better job. That is, we need reasonable ways to decompose parameter estimates and scale for ILMs or other model approaches. The takeaway 
Table 1.16 Aggregate sample conditional logit results

\begin{tabular}{lrrrc}
\hline Effect & Estimate & StdErr & T-Stat & $\mathrm{P}(\mathrm{T})$ \\
\hline asc1 & -0.2019 & 0.0498 & -4.2564 & 0.0000 \\
asc2 & -0.1509 & 0.0493 & -3.0605 & 0.0022 \\
asc3 & -0.1273 & 0.0503 & -2.5295 & 0.0115 \\
Flytime1 & 0.2862 & 0.0367 & 7.8047 & 0.0000 \\
Flytime2 & 0.0323 & 0.0386 & 0.8380 & 0.4020 \\
Flytime3 & -0.0622 & 0.0387 & -1.6091 & 0.1077 \\
Fare1 & 0.7680 & 0.0341 & 22.4905 & 0.0000 \\
Fare2 & 0.3186 & 0.0390 & 8.1662 & 0.0000 \\
Fare3 & -0.1983 & 0.0443 & -4.4796 & 0.0000 \\
Qantas & 0.0579 & 0.0391 & 1.4792 & 0.1392 \\
Virgin & -0.0595 & 0.0385 & -1.5455 & 0.1224 \\
Jetstar & 0.0200 & 0.0107 & 1.8611 & 0.0628 \\
Meals & -0.0324 & 0.0107 & -3.0109 & 0.0026 \\
Entertain & -0.0148 & 0.0109 & -1.3641 & 0.1727 \\
GetBags & 0.0539 & 0.0109 & 4.9483 & 0.0000 \\
FrqFlyer & -0.0059 & 0.0107 & -0.5505 & 0.5820 \\
\#Stops & 0.0115 & 0.0111 & 1.0417 & 0.2977 \\
\%OnTime & 0.0364 & 0.0110 & 3.3250 & 0.0009 \\
Alcohol & 0.0086 & 0.0109 & 0.7913 & 0.4289 \\
Drinks & -0.0577 & 0.0109 & -5.3110 & 0.0000 \\
Checkin & 0.0290 & 0.0377 & 0.7670 & 0.4431 \\
\hline
\end{tabular}

from these results is simply that the statistical results are consistent with the graphical results; both show differences in individual model estimates are partially related to error variability differences in people. Thus, ILM estimates do not represent pure preference differences unless one uses a modeling approach that can separate error variance (scale) and preferences.

Some takeaways for error variance differences within and between people include the fact that psychologists have known/observed that error variances differ within and between people for decades. It is now time to move away from the silly idea that unobserved utility is due to factors unobserved by analysts, and embrace the fact that people exhibit variability (or not!) in choices that is inherent to the way humans make choices. Some people in some situations will be more consistent; in other cases they will be less consistent. A clear opportunity exists to develop theory and/or empirical generalizations about how and why this occurs. CenSoC research teams have many examples of non-constant error variances, 
Table 1.17 MSR interactions with attributes

\begin{tabular}{lcccc}
\hline Mean Square Residual Interactions & & & \\
\hline Effect & Estimate & StdErr & T-Stat & P(T) \\
\hline Asc1*res & 0.9122 & 0.1380 & 6.6122 & 0.0000 \\
Asc2*res & 0.7525 & 0.1378 & 5.4619 & 0.0000 \\
Asc3*res & 0.4470 & 0.1451 & 3.0815 & 0.0020 \\
TT1*res & -0.4746 & 0.1168 & -4.0624 & 0.0001 \\
TT2*res & -0.0914 & 0.1202 & -0.7604 & 0.4471 \\
TT3*res & 0.1687 & 0.1196 & 1.4108 & 0.1584 \\
Fare1*res & -1.2471 & 0.1077 & -11.5755 & 0.0000 \\
Fare2*res & -0.6455 & 0.1226 & -5.2673 & 0.0000 \\
Fare3*res & 0.3727 & 0.1316 & 2.8312 & 0.0047 \\
Qan*res & 0.3297 & 0.1158 & 2.8464 & 0.0045 \\
Vir*res & -0.2928 & 0.1238 & -2.3651 & 0.0181 \\
Jet*res & 0.1781 & 0.1192 & 1.4935 & 0.1354 \\
\hline
\end{tabular}

including findings that error variances differ not only within/between folks, but also systematically with covariates like age, education, numeracy, etc. Recent results by Fiebig et al. (2010) and Salisbury and Feinberg (2010) show that failure to take error variance differences into account can lead to serious bias and misinference. More recently, CenSoC teams have found error variability differences associated with different DCE designs, and we expect a working paper on this topic on our website soon.

\section{STABILITY OF DCE CHOICES/PREFERENCES OVER TIME}

My final topic is a discussion of some initial results from a four wave study of the stability of DCE choices over time. Stability of preferences over time is important, but has rarely been studied for DCEs. Stability also is related to product category (type of good) maturity. For example, mature, wellestablished categories of goods and services should exhibit fairly stable preferences in the absence of shocks or major changes to the category. Preferences should be less stable for product or service categories that are new to markets and/or that undergo rapid or significant change(s).

In fact, the latter has been long seen in marketing as a major issue in studying preferences and/or using DCEs to predict real market behaviour (e.g., Urban, Weinberg and Hauser 1996). Many marketing academics 
understand that it does not make sense to ask people about products or services with which they are unfamiliar and/or have little experience as their answers will be unreliable and inaccurate. Urban, Weinberg and Hauser (1996) developed Information Acceleration (IA) to deal with these issues in new and emerging markets. IA seeks to "accelerate" consumers on the learning and experience path to get them to where they can provide sensible answers to surveys about new and emerging products and services. Urban et al. (1997) review several IA studies and provide compelling evidence that one can predict real market outcomes well with this approach.

I now briefly discuss a four wave choice stability study of three mature products: toothpaste, delivered pizza and laundry detergent. One expects DCE choices for these products to be stable, and to anticipate our initial results, they in fact are very stable. I also discuss three waves of ETS studies (discussed earlier), each about one year apart. Here one expects preferences to be less stable, although there has been ongoing, intense public discussion and debate about ETS in Australia for at least five years. I also discuss two waves of mobile phone DCEs mentioned earlier.

\subsection{Emissions trading plans}

The first ETS study (August 2008) involved 768 respondents from the Pureprofile online panel in Australia who each evaluated 16 pairs of ETS options described by five attributes. We used a BIBD to vary three of the four attributes, with starting year always present; so each person saw four attributes at a time. Wave two (May 2009) involved 3720 respondents from the Pureprofile panel who saw 24 pairs of ETS options described by all of the same five attributes. Each person received 16 common pairs from a fractional design plus eight more pairs drawn from the full $2^{5}$ factorial. Wave three (May 2010) involved 1760 respondents from the Pureprofile panel who evaluated 16, 20 or 24 choice sets with four ETS options, choosing their most and least preferred options in each set. Choice task examples are show in Figures 1.20 and 1.21 for pairs and quadruples, respectively.

Table 1.18 contains aggregate sample choice proportions associated with one (of two) attribute levels in each wave (the other is 1 minus the proportion). Figure 1.22 graphically compares the waves on all 10 common attribute levels. These results suggest choices of attribute levels were fairly stable for all three waves.

\subsection{Detergents, pizzas and toothpastes}

We recently completed four waves of this study, each wave six months apart. I focus on the first three waves, but the fourth wave also is similar. 


\section{Survey on Controlling Greenhouse Gases}

\begin{tabular}{|l|c|c|}
\hline Plan Features & Plan A & Plan B \\
\hline $\begin{array}{l}\text { The year that the plan begins (Higher cost with later } \\
\text { start date) }\end{array}$ & 2010 & 2012 \\
\hline $\begin{array}{l}\text { Use } 20 \% \text { of plan income to invest in RBD to more } \\
\text { cheaply reduce co2 }\end{array}$ & No & Yes \\
\hline Transport sector initially exempted/included & Yes & No \\
\hline Energy intensive sectors get special treatment & No & Yes \\
\hline
\end{tabular}

The government should implement (tick one)

C Plan A

c Plan B

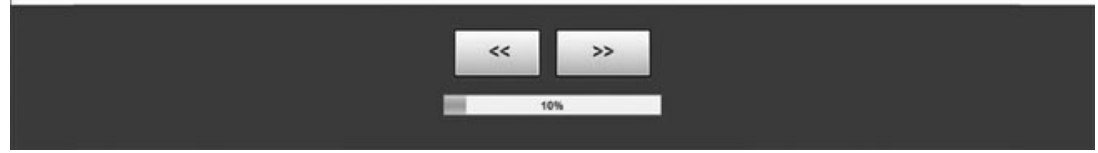

Figure 1.20 Example ETS DCE choice task for pairs

\begin{tabular}{|c|c|c|c|c|}
\hline & Plan A & Plan B & Plan C & Plan D \\
\hline Start Year & 2011 & 2011 & 2013 & 2013 \\
\hline Revenue Allocation & Lower GST & Reduce business taxes & $\begin{array}{l}\text { Give to low income } \\
\text { households/seniors }\end{array}$ & $\begin{array}{l}\text { Improve government } \\
\text { services and reducing } \\
\text { deficit }\end{array}$ \\
\hline $\begin{array}{l}\text { Method of } \\
\text { Implementing Carbon } \\
\text { Reductions }\end{array}$ & Carbon Trading Scheme & Hybrid Scheme & Technology Standard & Carbon Tax \\
\hline $\begin{array}{l}\text { International Role for } \\
\text { Australia }\end{array}$ & $\begin{array}{l}\text { Begin large carbon } \\
\text { reductions now }\end{array}$ & $\begin{array}{l}\text { Wait until China and } \\
\text { United States commit }\end{array}$ & $\begin{array}{l}\text { Wait until China and } \\
\text { United States commit }\end{array}$ & $\begin{array}{l}\text { Begin large carbon } \\
\text { reductions now }\end{array}$ \\
\hline $\begin{array}{l}2020 \text { Emission } \\
\text { reduction targets }\end{array}$ & $5 \%$ & $5 \%$ & $25 \%$ & $25 \%$ \\
\hline \multicolumn{5}{|c|}{ Which ONE of the 4 plans above is your MOST preferred choice? (tick one) } \\
\hline & Plan A & Plan B & Plan C & Plan D \\
\hline
\end{tabular}

Figure 1.21 Example ETS DCE task for quadruples

Figure 1.23 graphs the aggregate conditional logit model estimate results, but choice proportions for each option in each choice set also graph on top of one another for all four waves. The results show aggregate choices/ preferences were very stable over all four waves.

Finally, to save space, I summarize results for the two mobile phone 
Table 1.18 Comparison of choices by ETS DCE wave (\%)

\begin{tabular}{lccc}
\hline Attribute Level & Wave 1 & Wave 2 & Wave 3 \\
\hline Start Date (Soon v. Later) & 57.1 & 54.6 & 52.8 \\
Redistribute (GST v. Seniors/Poor) & 48.4 & 49.0 & 44.0 \\
Transport (Initial Exempt v. Not) & 50.6 & 49.5 & 50.4 \\
20\% R\&D (Yes v. No) & 58.7 & 56.2 & 53.2 \\
Energy Sectors (Special treatment v. No) & 53.7 & 52.9 & 50.6 \\
\hline
\end{tabular}

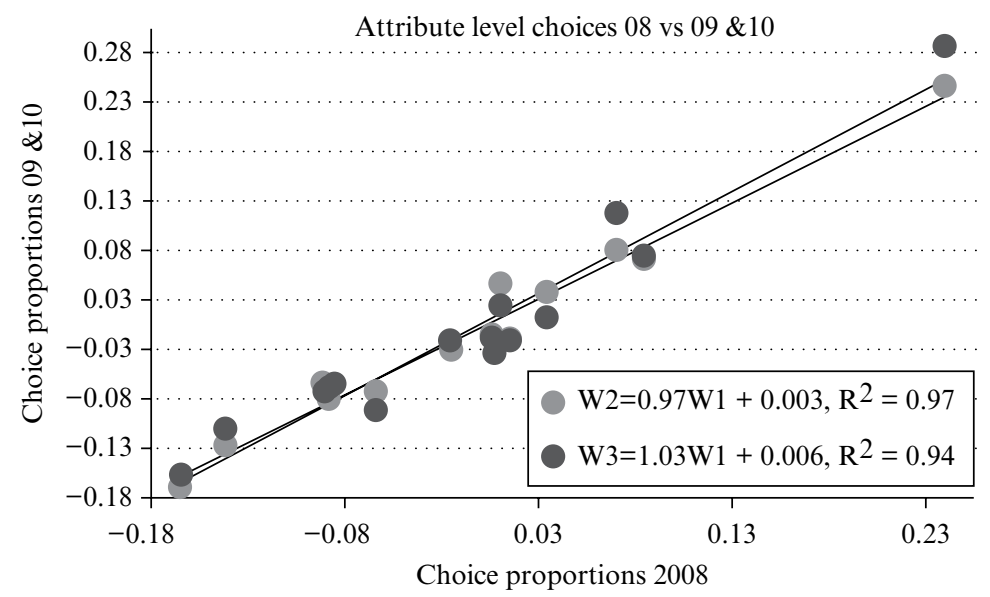

Figure 1.22 Graphical comparison of choice proportions for 3 ETS DCE waves

waves; as before, the choice proportions by choice option and choice set lie on top of one another, and the aggregate conditional logit model estimates are proportional and highly correlated. Thus, all relatively mature product categories studied exhibit high levels of choice/preference stability over time.

As a final comment, there is NO evidence in any of our work over the past 20 years for "constructed preferences" (e.g. Bettman and Zins 1977; Bettman et al., 1998). It may be that such preferences are associated with new and unfamiliar products/choice tasks and/or result from demand artifacts, such as not using methods like Information Acceleration (Urban et al., 1997) to create a common experience base and avoid confounding experience and familiarity differences with real preferences differences.

I also have designed several DCEs to study changes in preferences during the course of a DCE. This requires controlling for order effects, 
Toothpaste: MNL mean Vs MNL estimates

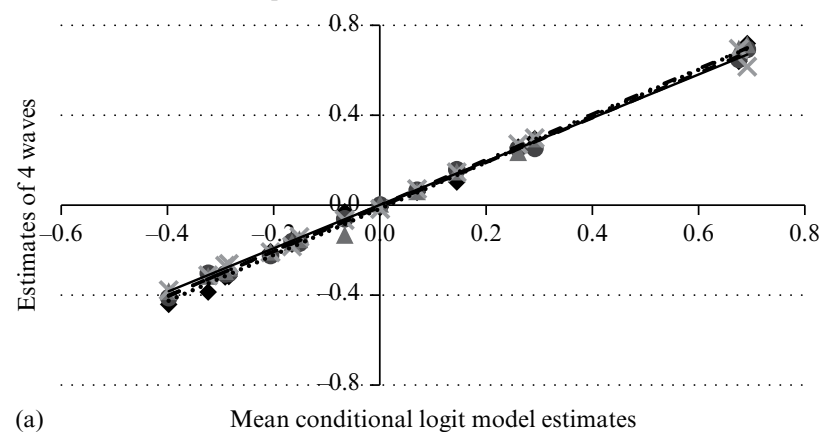

(a)
- Wave 1

- Wave 2

- Wave 3

$\times \quad$ Wave 4

$\mathrm{y}_{1}=1.0281 \mathrm{x}$

$\mathrm{R}^{2}=0.9942$

- - - $\mathrm{y}_{2}=0.9916 \mathrm{x}$

$\mathrm{R}^{2}=0.9979$

- - - $\mathrm{y}_{3}=1.0132 \mathrm{x}$

$\mathrm{R}^{2}=0.9962$

$\mathrm{y}_{4}=0.9671 \mathrm{x}$

$\mathrm{R}^{2}=0.9952$
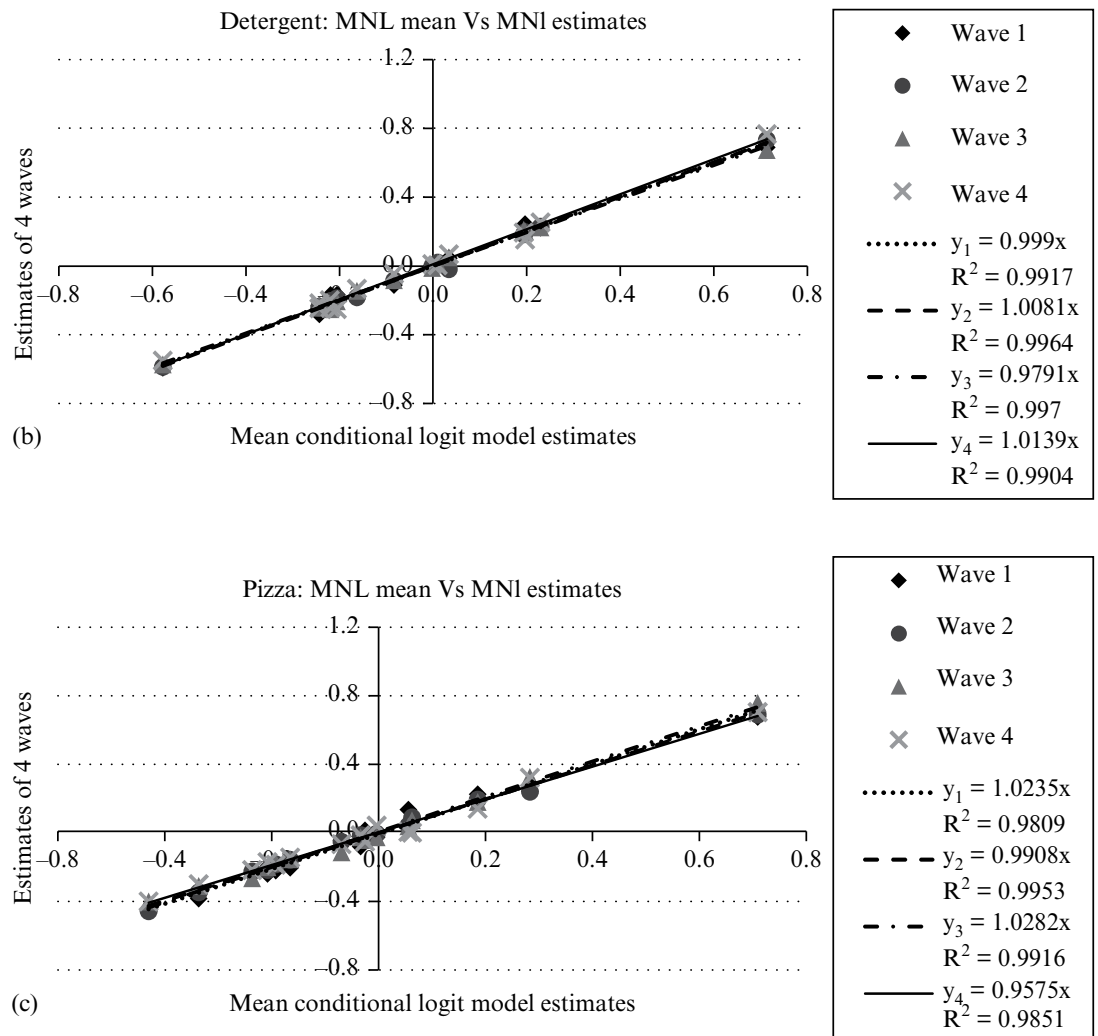

Figure 1.23 MNL model estimates by wave and category 
and one way to do that is to use a latin square design to make versions of a DCE, randomly assigning participants to them. A "version" is a different ordering of choice sets, and latin square designs insure that each choice set appears in each order and co-appears in these orders with every other choice set. Louviere and Eagle (2006) reported some of these results; in every order experiment we conducted preferences did not change. Instead, what changed was the error variance: it typically was high initially, declined rapidly and stabilized; and with sufficiently many choice sets, it rose again towards the end of the DCE task. Naturally, if one does not take systematic differences in error variances associated with order into account it will "look" as if preferences change over the course of a DCE even when this does not occur. The takeaway is that one should ask serious and critical questions about experimental results based on simplistic experiments, experimental implementations and analytical methods.

The takeaways from DCE preference stability over time and order effects is that choice set order impacts choice/preference variability more than time waves for relatively mature products and services. However, one must control for error variability (choice consistency) differences over time, order and other factors to obtain unbiased estimates of the underlying preference process. Indeed, Salisbury and Feinberg (2010) give a dramatic example of this, showing almost all prior work in psychology and other fields on intertemporal discounting is likely to be biased and incorrect due to failure to take error variability differences into account. They showed (not surprisingly) that experimental participants were more inconsistent in making choices about future events than current ones, leading prior researchers to conclude that "discounting" occurred, when it didn't.

\section{DISCUSSION AND CONCLUSIONS}

I discussed several themes in this chapter: developing models for individual choosers, estimating choice variability within and between people, and stability of choices over time and order. My and others' work on individual-level models strongly suggests that the field needs to move away from what can be characterized as a largely "top-down" statistical modeling focus towards a more "bottom-up" focus that seeks to understand underlying decision and choice processes. Fitting choice data and predicting well is not difficult, and the reasons why top-down models do well have been known since the seminal work of Dawes and Corrigan (1974), which unfortunately seems largely ignored outside of psychology. Dawes and Corrigan showed that linear regression models always fit response data well and predict well in-sample if attributes are motonically 
related to responses and/or can be transformed to be monotonic. They also showed that very incorrect linear models can consistently outperform "correctly specified" models in the presence of errors when attributes are monotonically related to responses. The latter conditions almost always apply to DCEs and to real markets. Thus, researchers should take no comfort in how well models fit, nor whether signs on estimates agree with a priori expectations, etc. The field needs to focus on process and descriptive, behavioural models, not statistical representations of what are almost certainly incorrect model specifications of decision rules.

For example, I showed data for certain DCE respondents, virtually all of whom chose options based on one particular attribute level or did not choose any options with certain other levels. Such results are common in our DCE work, with one extreme being a project in which over 95 per cent of $900+$ respondents made choices in a perfectly deterministic manner, using a small number of rules that can be used to predict well over 90 per cent of the observed choices correctly. The rules to which I refer were similar to "if cost is low and attribute 1 is 'high' then say 'yes', otherwise say "no"'. The fact that we have proofs that certain mixtures of distributions of parameters can approximate any choice process does not in fact tell us much about such processes, providing a false sense of academic security that somehow we "understand" such processes, when in fact we don't. So, the key reason to develop the ability to model individuals is not to simply do what we've been doing with random parameter models, but instead to allow us to obtain much richer insights into what individuals actually do.

I illustrated some of these issues in the brief section on observing and measuring choice variability (error) differences in people. That is, evidence has been growing steadily since 1990 that there are large differences between and within people in how consistently they make DCE choices (or real world choices). Non-constant error variances matter in all limited dependent variable models, of which choice models are one type. I showed three examples in which mean squared residuals for sampled individuals correlated highly with model parameter estimates for the same people. This strongly suggests that a significant portion of what has been claimed to be utility or preferences is in fact error variability differences between people. These examples are the rule, not the exception in our research over the past five or more years. Naturally, some portion of the error variability I showed is due to model misspecification, which clearly should be a focus of future research. The results I presented are not unique to the modeling approach I used because one can use random parameter models to estimate parameters for each individual in a sample, and use these estimates to calculate squared residuals from model predictions for each person. If 
one graphs these residuals against model estimates, one gets graphs very similar to those I showed. So, sophisticated random parameter models are not the answer to separating preferences from scale. We need much more work on this, and I think a significant portion of this work should focus on modeling individuals directly so that we can learn something about process and in so doing decrease model misspecification errors.

I also briefly discussed choice stability over time, giving several examples from our research program on repeated DCE choices for the same people and the same DCEs, as well as different random samples over time responding to the same DCEs. The comparisons strongly support stability of aggregate choices over time for relatively mature products. A CenSoC research team should soon finalize a paper on our work funded by SSHRC in Canada on four waves of the same and different people over two years for three product categories. I can say that the only change over time is a systematic tendency for error variability to decline over the four waves. Choice proportions for each option in each choice set are proportional and highly correlated wave on wave. The design approach we used also allows us to observe the choice proportions associated with each of 16 options that vary over the choice sets and compete with one another. They also exhibit a systematic tendency to become more consistent over time, and they also are proportional to one another and highly correlated.

Other work on order effects in DCEs used latin square designs to control for order, such that each choice set appears in each order equally often. This allows one to extract and estimate separate choice models for each order position. If one designs DCEs in this way, one finds no differences in model estimates except for error variability differences: error variability is initially high, drops rapidly with order, stabilizes, and for longer DCEs, it typically rises towards the end of the order. Thus, we find no evidence for constructed preferences and the like; instead, we find clear evidence of error variability differences by order. If one does not take such differences into account, it will "look" to naïve researchers as if preferences are changing.

Many will see my comments and examples as "problems", particularly in so far as they call into question much prior work. However, I view them instead as "opportunities" as well as a call for more research into process fundamentals and a serious change in the focus of our work in choice modeling towards individuals and away from mere statistical description of choices. I look forward to watching the evolution of the field in these directions. 


\section{NOTE}

1. I gratefully acknowledge the assistance of Bart Frischknecht and Christine Eckert in preparing this chapter.

\section{REFERENCES}

Beggs, Cardell and Hausman (1981) "Assessing potential demand for electric cars," Journal of Econometrics, 16, 1-19.

Bettman, J.R. and M.A. Zins (1977) "Constructive processes in consumer choice," Journal of Consumer Research, 4, 75-85.

Bettman, J.R., M. Luce and J. Payne (1998) "Constructive consumer choice processes,” Journal of Consumer Research, 25, 187-217.

Chapman, R. and R. Staelin (1982) "Exploiting rank ordered choice set data within the stochastic utility model," Journal of Marketing Research, 19 (3), 288-301.

Chapman (1984) "An approach to estimating logit models of a single decision maker's choice behavior," Advances in Consumer Research, 11, 656-661.

Dawes, R.M. and B. Corrigan (1974) "Linear models in decision making," Psychological Bulletin, 81 (2), 95-106.

Ebling, C., Frischknecht, B. and J.J. Louviere (2010) "Keep it simple: easy ways to estimate choice models for single consumers," Proceedings of the Australia-New Zealand Marketing Academy.

Fiebig, D.G., Keane, M.P., Louviere, J.J. and N. Wasi (2010) "The generalized multinomial logit model: accounting for scale and coefficient heterogeneity," Marketing Science, 29 (3), 393-421.

Finn, A. and J.J. Louviere (1992) "Determining the appropriate response to evidence of public concern: the case of food safety," Journal of Public Policy and Marketing, 11 (2), 12-25.

Frischknecht, B., Eckert, C., Louviere, J.J. and J. Geweke (2011a) "Incorporating prior information to avoid complete separation problems in estimating discrete choice models," CenSoC Working Paper No. 11-007, (http://www.censoc.uts. edu.au/researchoutput/paper.html).

Frischknecht, B., Eckert, C. and J.J. Louviere (2011b) "Simple ways to estimate choice models for single individuals," CenSoC Working Paper No. 11-006 (http://www.censoc.uts.edu.au/researchoutput/paper.html).

Green, P.E. (1974) "On the design of choice experiments involving multifactor alternatives," Journal of Consumer Research, 61-68.

Green, P.J. (1984) "Iteratively reweighted least squares for maximum likelihood estimation, and some robust and resistant alternatives," Journal of the Royal Statistical Society. Series B (Methodological), 149-192.

Hauser, J.R. (1978) "Consumer preference axioms: behavioral postulates for describing and predicting stochastic choice," Management Science, 24 (13), 1331-1341.

Heckman, J. (1979) "Sample selection bias as a specification error," Econometrica, 47 (1), 153-61.

Hensher, D.A. and J.J. Louviere (1983) "Identifying individual preferences for 
international air fares: an application of functional measurement theory," Journal of Transport Economics and Policy, 17 (3), 225-245.

Hensher, D.A., Louviere, J.J. and J. Swait (1998) "Combining sources of preference data," Journal of Econometrics, 89 (1-2), 197-221.

Lancsar, E. and J.J. Louviere (2008) "Estimating individual level discrete choice models and welfare measures using best worst choice experiments and sequential best worst MNL," CenSoC Working Paper No. 08-003 (http://www.censoc.uts. edu.au/researchoutput/paper.html).

Louviere, J.J. (1988) “Analyzing decision making: metric conjoint analysis," Sage university papers series No. 67: Quantitative Applications in the Social Sciences, Thousand Oaks, CA: Sage Publications, Inc.

Louviere, J.J. (1994) “Conjoint analysis," in R. Bagozzi (ed.), Advanced Marketing Research, Cambridge, MA: Blackwell Publishers.

Louviere, J.J. and T. Eagle (2006) "Confound it! That pesky little scale constant messes up our convenient assumptions," Proceedings, 2006 Sawtooth Software Conference, 211-228, Sawtooth Software, Sequim, Washington, USA.

Louviere, J.J. and G.G. Woodworth (1983) "Design and analysis of simulated consumer choice or allocation experiments," Journal of Marketing Research, 20, 350-367.

Louviere, J.J., Hensher, D.A. and J. Swait (2000) Stated Choice Methods: Analysis and Application, Cambridge, UK: Cambridge University Press.

Louviere, J.J., Street, D., Burgess, L., Wasi, N., Islam, T. and A.A.J. Marley (2008) "Modeling the choices of individual decision-makers by combining efficient choice experiment designs with extra preference information," Journal of Choice Modelling, 1 (1), 128-163.

Luce, R.D. (1959) Individual Choice Behavior: A Theoretical Analysis, New York: Wiley.

Luce, R.D. and P. Suppes (1965) "Preference, utility, and subjective probability," in Luce, R.D., Bush, R.R. and E. Galanter (eds), Handbook of Mathematical Psychology, vol. 3, New York: Wiley, pp. 249-410.

Magidson, J., and Vermunt, J.K. (2007) "Removing the scale factor confound in multinomial logit choice models to obtain better estimates of preference," Sawtooth Software Conference Proceedings, Sequim, WA: Sawtooth Software, Inc.

Manski, M., and D.L. McFadden (1981) “Alternative estimators and sample designs for discrete choice analysis," Chapter 1 in Manski, M., and D.L. McFadden (eds), Structural Analysis of Discrete Data and Econometric Applications, Cambridge: The MIT Press, pp. 2-50.

Marley, A.A.J. (1968) "Some probabilistic models of simple choice and ranking," Journal of Mathematical Psychology, (5), 311-32.

Marley, A.A.J. and J.J. Louviere (2005) "Some probabilistic models of best, worst, and best-worst choices," Journal of Mathematical Psychology, 49 (6), $464-480$.

Marley, A.A.J. and D. Pihlens (2012) "Models of best-worst choice and ranking among multiattribute options (profiles)," Journal of Mathematical Psychology, $56(1), 24-34$.

Marley, A.A.J., Louviere, J.J. and T.N. Flynn (2008) "Probabilistic models of set-dependent and attribute-level best-worst choice," Journal of Mathematical Psychology, 52, 281-296.

Marshall, Chan and Curry (2011) "A head-to-head comparison of the tradi- 
tional (top-down) approach to choice modeling with a proposed bottom-up approach," 2010 Sawtooth Software Conference Proceedings, 309-319.

Salisbury, L. and F.M. Feinberg (2010) "Alleviating the constant stochastic variance assumption in marketing research: theory, measurement and experimental test," Marketing Science, 29 (1), 1-17.

Scarpa, R., Raffaelli, R., Notaro, S. and J.J. Louviere (2011) "Exploring scale effects of best/worst rank ordered choice data to estimate benefits of tourism in alpine grazing commons," American Journal of Agricultural Economics, 10, $1-16$.

Street, D. and L. Burgess (2007) The Construction of Optimal Stated Choice Experiments: Theory and Methods, New York: John Wiley, Inc.

Swait, J. and J.J. Louviere (1993) "The role of the scale parameter in the estimation and comparison of multinomial logit models," Journal of Marketing Research, 30, 305-314.

Thurstone, L.L. (1927) “A law of comparative judgement," Psychological Review, 34 (4), 278-286.

Toubia, O., J.R. Hauser and R. Garcia (2007) "Probabilistic polyhedral methods for adaptive choice-based conjoint analysis: theory and application," Marketing Science, 26 (5), 596-610.

Urban, G.L., Weinberg, B.D. and J.R. Hauser (1996) "Premarket forecasting of really-new products," Journal of Marketing, 60 (1), 47-60.

Urban, G.L., Hauser, J.R., Qualls, W.J., Weinberg, B.D., Bohlmann, J.D. and R.A. Chicos (1997), "Information acceleration: validation and lessons from the field,” Journal of Marketing Research, 61 (1), 143-153. 